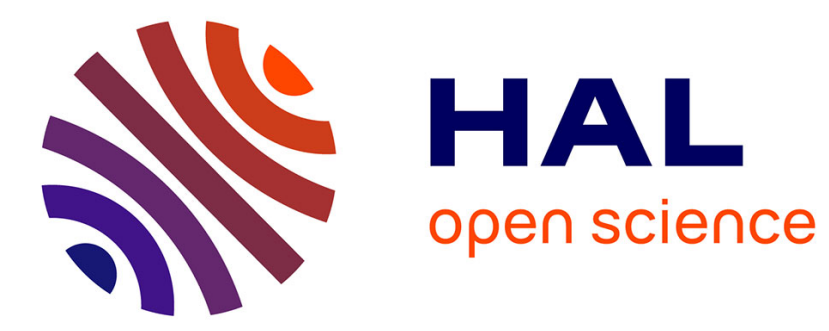

\title{
Modification of Lu's (2005) high pressure model for improved high pressure/high temperature extrapolations. Part II: modeling of osmium-platinum system at high pressure/high temperature
} Jean-Marc Joubert, Jean-Claude Crivello, Kirill V Yusenko

\section{To cite this version:}

Jean-Marc Joubert, Jean-Claude Crivello, Kirill V Yusenko. Modification of Lu's (2005) high pressure model for improved high pressure/high temperature extrapolations. Part II: modeling of osmium-platinum system at high pressure/high temperature. Calphad, 2021, 74, pp.102311. 10.1016/j.calphad.2021.102311 . hal-03295413

\section{HAL Id: hal-03295413 \\ https://hal.science/hal-03295413}

Submitted on 22 Jul 2021

HAL is a multi-disciplinary open access archive for the deposit and dissemination of scientific research documents, whether they are published or not. The documents may come from teaching and research institutions in France or abroad, or from public or private research centers.
L'archive ouverte pluridisciplinaire HAL, est destinée au dépôt et à la diffusion de documents scientifiques de niveau recherche, publiés ou non, émanant des établissements d'enseignement et de recherche français ou étrangers, des laboratoires publics ou privés. 
Modification of Lu's (2005) high pressure model for improved high pressure/high temperature extrapolations. Part II: modeling of osmium-platinum system at high pressure/high temperature

Jean-Marc Joubert ${ }^{1}$, Jean-Claude Crivello ${ }^{1}$, Kirill V. Yusenko ${ }^{2}$

${ }^{1}$ Univ Paris Est Creteil, CNRS, ICMPE, UMR 7182, 2 rue Henri Dunant, 94320 Thiais, France

${ }^{2}$ BAM Federal Institute for Materials Research in Testing, Department 6.3. Structure Analysis, Richard-Willstätter-Str. 11, 12489 Berlin, Germany

e-mail address of corresponding author: joubert@icmpe.cnrs.fr

\begin{abstract}
In Part I of this paper, we have described a modification brought to the model of Lu (X.-G. Lu et al., Comput. Coupling Phase Diagr. Thermochem. 29 (2005) 49-55) in order to avoid extrapolation problems at high pressure and temperature. We now extend this approach to the study of a binary system: Os-Pt. For this, a complete description (equation of state) of Os at high pressure/high temperature is provided including the liquid phase. The thermodynamic assessment of the system Os-Pt has been carried out at ambient pressure by the Calphad method. All this study has been supported by first principles, special quasi-random structure (including under high pressure) and phonon calculations. Finally, using the high pressure description of metastable structures (hcp Pt and $f c c$ Os), we have been able to obtain by extrapolation a complete description of Os-Pt system up to $500 \mathrm{GPa}$. Recent experimental data for Os-Pt system obtained up to $50 \mathrm{GPa}$ at various temperatures up to $2300{ }^{\circ} \mathrm{C}$ may us allow to validate our modeling approach.
\end{abstract}

Keywords: Calphad, model, EOS, DFT, osmium, high pressure, osmium-platinum

\title{
1. Introduction
}

Os-Pt system is attractive for different reasons. Like many other multimetallic systems based on platinum group metals, it has been proposed as active and selective catalytic system for $\mathrm{CO}$ oxidation [1-3]. Platinum group metals attract attention as elements with high melting points and low pressure compressibility which might be comparable with diamond for Os. Pressure and temperature dependent phase stability and phase transformations of pure platinum group metals and especially their binary and multicomponent alloys have importance to understand the formation of multicomponent metallic minerals such as iridosmine, ferroplatinum and related mineralogical individuals. Platinum group metallic minerals form under high-pressure in Earth mantle and represent non-equilibrium phases under ambient conditions [4]. Osmium-based alloys systems are also important to understand the behavior of platinoid metals in the earth mantle, and because $h c p$ Os is an analogue to hcp Fe (with additional filled $4 f$ bands) for the study of the earth core [4]. These two latter applications require not only the knowledge of the phase diagram but also its modifications at ultra high hydrostatic pressure above $100 \mathrm{GPa}$. From the experimental point of view, several platinoid systems at high pressure have already been studied up to $140 \mathrm{GPa}$ at room temperature and upon heating above $3000{ }^{\circ} \mathrm{C}$ [5-8]. Os-Pt system has been also studied up to $50 \mathrm{GPa}$ and $2300{ }^{\circ} \mathrm{C}$ [9]. Experimental investigation of binary phase diagrams based on refractory hexagonal close packed ( $h c p: \mathrm{Os}, \mathrm{Re}, \mathrm{Ru}$ ) metals as the first component and face-centered cubic (fcc: Ir, Pt, Rh) refractory metals as the second component requires careful analysis due to the presence of a two- 
phase domain between $h c p$ and fcc alloys. The most important is to understand the changes of the mutual solubilities with pressure. In general, along compression the two-phase domain should shift towards the metal with larger atomic volume [4]. Such trend has been confirmed for Ir-Os and Ir-Re binary alloys, where metals have close atomic volumes and significantly different compressibility (IrOs binary alloys) or different atomic volumes and nearly identical compressibility (Ir-Re binary alloys) [5-8]. Os-Pt system represents significant differences in atomic volumes and compressibility and shows that upon compression the two-phase field becomes more narrow with pressure [9]. The aim of the present work is to provide a thermodynamic description of this system by the Calphad method including the modeling at high pressure. This is also a concrete application of the modifications provided to Lu's (2005) model [10] in the first part of this study [11]. Os-Pt is a relatively simple system prone to a comprehensive thermodynamic analysis. It does not contain intermetallic compounds but the metastable structures of the two constituting elements ( $h c p$ Pt and fcc Os) should be described.

\section{Modelling and calculation details}

\subsection{High pressure model}

The model developed by Lu et al. was used [10]. In the first part of this study [11], we introduced modifications in order to avoid wrong extrapolations of the $C_{p}$ and entropy when both high pressure and temperature are used. The modification consists in introducing two exponential terms in order to damp the temperature dependent terms of the average linear thermal expansion $(\alpha)$ and compressibility at pressures above certain cut-off pressures.

\subsection{DFT calculations}

Density Functional Theory (DFT) calculations were carried out using the Vienna Ab-initio Simulation Package (VASP) $[12,13]$ with projector augmented waves (PAW) [14] by applying 3 sets of exchange and correlation (XC) functionals: the Local Density Approximation (LDA) [15] and the Generalized Gradient Approximation (GGA) with the Perdew-Burke-Ernzerhof (PBE) [16] and the PBE revised for solids (PBEsol) [17].

For pure Os and Pt metals, an energy cut-off of $800 \mathrm{eV}$ for the plane wave basis sets was used. For each phase considered, i.e. $f c c$ and $h c p$, a high dense grid of k-points in the irreducible wedge of the Brillouin zone was generated with the Monkhorst-Pack scheme [18]. The total energy convergence was assured up to $10^{-6} \mathrm{eV}$, using enough relaxation cycles to reduce the residual interatomic forces under $10^{-8} \mathrm{eV} \cdot \AA^{-1}$. Then, Quasi-Harmonic Phonon Approximation (QHA) calculations within the supercell approach [19] $(3 \times 3 \times 3)$ were performed to determine the volume-temperature dependence. The Phonopy code was used to determine the interatomic force constants from the VASP calculated interatomic forces [20]. The vibrational Helmholtz energy $F(V, T)$ and its derived thermodynamic variables $(V(T), B(T), \alpha(T))$ were obtained from harmonic contribution calculated at 11 different volumes, with independent cell shape optimization in the case of the $h c p$ structure. This latter approach is a simplification of the traditional method consisting in obtaining the EOS from the computed full grid of $(V, c / a)$ like recently done on Os [21]. Several pressurized structures such as metastable fcc Os and $h c p \mathrm{Pt}$, presenting imaginary frequencies, were neglected in the thermodynamic treatments. 
The Os-Pt binary $f c c$ and $h c p$ solutions were considered using the Special Quasi-Random Structure (SQS) method providing a random-like distribution of both atoms in a limited and reasonable cell size [22]. The classical 16-atom SQS cells were considered for 3 binary compositions $(1 / 4,1 / 2,3 / 4)$ of $f c c$ and $h c p$ phases [23] [24] in addition to single atom substitution (1/16, 15/16). The DFT calculations on SQS cells were performed using VASP in comparable approximations (convergence parameters, relaxation preserving the original symmetry) as for pure elements except that only PBE and PBEsol functionals have been used. In addition, the study of the energy variation as a function of volume (pressurized cells) has been investigated for the 5 binary compositions. This compression has been applied to the SQS cells and pure elements in order to obtain the enthalpy of mixing (by total energy difference) and the cell volume in the $f c c$ and $h c p$ structures at different pressures. Since the calculations cannot be done for each structure at the same pressure, both energies and volumes were fitted as a function of pressure with a $4^{\text {th }}$ degree polynomial allowing a recalculation at given pressures.

\section{Selection of data}

\section{$3.10 \mathrm{~s}$}

Osmium is a truly interesting element since it combines the largest bulk modulus [25] among metals (it is only slightly smaller than diamond) and the largest density [26] among all elements.

\subsection{1 hcp}

The list of experimental data can be found in Table 1. The molar volume and thermal expansion function of $T$ have been carefully reviewed by Arblaster [27] (a recent review of the thermodynamic properties by the same author is also available [28]). The assessed data will be used as experimental data for the present assessment. This offers the advantage of a proper correction of the different temperature scales used in the older literature, a proper conversion from $\mathrm{KX}$ to $\AA$ when appropriate, a careful selection of the most accurate data and an assessment along the temperature range covered by the experiments (1300 K).

The room temperature compressibility has been studied by numerous authors [25, 29-35] motivated by the fact that Os is the most incompressible metal and close to be as hard as diamond. Higher volumes are observed by Cynn et al. [29], Armentrout and Kavner [33] and Perreault et al. [35] yielding a too high bulk modulus. On the other hand, the measurements by Kenichi [30] and Occelli et al. [31] are a bit lower than the most recent data of Voronin et al. [32], Godwal et al. [34] and Dubrovinsky et al. [25].

Compressibility at high temperature was measured by both Armentrout and Kavner [33] and Voronin et al. [32]. The measurements of Armentrout et al. have been found to be very scattered and inconsistent not only with other authors (at $300 \mathrm{~K}$ in particular) but also with themselves (different volumes for similar pressures and temperatures, decreasing volumes as a function of temperature at constant pressure...). They have not been considered.

The ultrasonic measurement of the bulk modulus as a function of temperature of Pantea et al. [36] is not used because the value of $\mathrm{d} B / \mathrm{d} T$ at $300 \mathrm{~K}(-0.019 \mathrm{GPa} / \mathrm{K})$ is inconsistent with other measurements $(-0.060 \mathrm{GPa} / \mathrm{K}[32]$ and $-0.054 \mathrm{GPa} / \mathrm{K}$ [33]), and with the DFT calculations from this work $-0.049 \mathrm{GPa} / \mathrm{K})$. 
Osmium has been the subject of numerous DFT calculation studies [21, 25, 37-46] using different techniques and approximations (see Table 2). Our own calculations will be presented in the next section.

In spite of undeniable successes in the reproduction of experimental data (see e.g. the comparison between the extremely high pressure volumes calculated by Joshi et al. with full-potential LAPWGGA [39] with the experimental data of Dubrovinsky et al. [25]), there are many problems related to the use of DFT data in thermodynamic assessment when combined with experimental measurements.

Among them, one may cite the wrong volume calculation (e.g. an offset should be applied to the volume from Joshi et al. to compare with that of Dubrovinsky et al.), wrong bulk modulus (LDA is often too hard) e.g. $70 \mathrm{GPa}$ difference in Ref. [37], the difficulty to choose among the methods (full potential FP versus pseudo-potential PP, PAW versus ultrasoft USPP) and the most convenient XC functionals (LDA, PBE, PBEsol, ...), calculation conditions that may be good for certain properties but give a worse estimate of other properties. This leads to differences between authors (Joshi et al. with FP-LAPW-GGA is much closer to the experiments of Dubrovinsky et al. [25] than Burakovsky et al. [47] with GGA-PBE) without a clear picture of which calculation should be preferred. Our own calculation presented in the next section have the merit of having been done with different functionals in the same conditions, so a fair comparison is possible.

In conclusion, when experimental measurements are available, they will always be preferred. DFT data will be useful to capture the trends when experimental data is missing or is limited in a given range (e.g. $\alpha(T)$ at high pressure, $V(p)$ at high temperature, $B(T), B(p))$.

\subsection{2 liquid}

The melting curve has been predicted using $a b$ initio quantum molecular dynamics calculations using the so-called $\mathrm{Z}$ method up to $500 \mathrm{GPa}$ [47]. This method has been found to be very accurate in the case of Pt (see Part I). The calculated initial slope is $50 \mathrm{~K} / \mathrm{GPa}$ is in relative agreement with estimated values reported in the literature $[48,49]$. Joshi et al. [39] determined the melting point according to Lindemann's law i.e. without any knowledge of the properties of the solid phase. Moreover, these authors have been criticized by Burakowsky et al. for their unphysical choice of the Grüneisen parameter. The only experimental data is a recent measurement up to $35 \mathrm{GPa}$ [50] in excellent agreement with Burakowsky et al. confirming the validity of the calculation.

Paradis et al. [51] measured the volume of the liquid phase close to the melting point using imaging techniques of a levitated sample. Since the volume of the solid phase has been assessed experimentally only up to $1300 \mathrm{~K}$ [27], the volume change at the melting point cannot be determined accurately making difficult the estimation of the initial slope of the melting curve using the Clapeyron relationship.

Note that the definition of the melting point of osmium itself is still debated in the literature. We stick to the SGTE description with a melting point at $3306 \mathrm{~K}$ while Arblaster [52] and Burakowsky et al. [47] think it is the value for impure Os and propose a higher value around $3400 \mathrm{~K}$.

\subsection{Os-Pt}


Os-Pt binary system was originally studied by Voronova et al. [53]. These authors showed that the system is peritectic. The peritectic temperature was determined as well as the $f c c$ solidus and the solubility in the $f c c$ solid solution. The solubility of Pt in the $h c p$ solid solution is unknown but less than 12 at.\%. Rudman [54] reports the lattice parameters of $f c c$ solid solutions containing 10 and 20 at.\% Os prepared at $1973 \mathrm{~K}$ corroborating the findings of Voronova et al.. He also reports lattice parameters of the $h c p$ solid solution containing 5 and 10 at.\% Pt prepared at $2773 \mathrm{~K}$, indicating that the solubility may be of the order of or larger than 10 at.\% at this temperature. Non-equilibrium samples were obtained from inorganic precursors at $2273 \mathrm{~K}$ and 1.5-2 GPa by Gromilov et al. [55]. They agree with the previous reports as far as the solubility of Pt ( 11 at.\%) in the $h c p$ solid solution is concerned but not concerning the osmium solubility ( 44 at.\%) in the fcc solid solution. A high pressure experimental study of the system has been recently published by Yusenko et al. [9] using samples obtained from single-source inorganic precursors. The data will be compared with our calculations in the discussion section below.

\section{Results}

All the model parameters, fitted with the Parrot module of Thermo-Calc, are provided in Table 3.

\subsection{Os at high pressure and high temperature}

\subsection{1 hcp Os}

DFT results showing the comparison between the three different exchange and correlation functionals are shown in Supplementary Data. Whereas the LDA leads to an "overbinding" effect (lattice constants too small, elastic constant too stiff), the GGA "overcorrects" this effect as known from the literature. It appears that modified PBEsol functional allows a far better reproduction of experimental data than any other functional. Comparison of PBEsol with experimental data and the thermodynamic assessment will be shown in the next figures.

The selection of data has already been addressed in Section 3.1.1. The thermodynamic assessment was mainly done considering the data of Arblaster [27] for volume-temperature dependence, Dubrovinsky et al. [25] for room temperature compressibility data and Voronin et al. [32] for high temperature compressibility. For the volume and thermal expansion, we preferred to use the compiled data by Arblaster [27] instead of each individual author because many confusion is present in the literature and because Arblaster evaluated and corrected in the best way the available data from e.g. the international temperature scale and ambiguities caused by the change from kX to $\AA$.

As the experimental data were limited, we used several DFT calculated values. The temperature and pressure dependence of thermal expansion from Ref. [44] was also selected. This author was chosen in preference to others giving the same type of calculation [40-43] because it reproduces reasonably well the thermal expansion at ambient pressure and because it has intermediate values between the other authors. This data together with the high temperature compressibility [32] allowed to assess the cut-off pressure in the model (parameter $p_{\mathrm{cut} /}^{\mathrm{Os}}$ ). The bulk modulus temperature dependence was taken from the same authors, first, for consistency and, second, because their value at $300 \mathrm{~K}$ matches well the one fitted from experiments.

The assessed data are presented in Figs. 1 to 5. With the simple model used, it is not possible to describe the low temperature data for e.g. the lattice expansion. Otherwise, the overall agreement is very good. The optimized bulk modulus at $300 \mathrm{~K}$ is $400 \mathrm{GPa}$. 


\subsection{2 liquid Os}

For liquid osmium, the only available reliable experimental data is from Paradis et al. [51]. It is fitted by the model but a constraint has been applied so that the volume of the liquid phase is always larger than that of the $h c p$ phase. Molar volume at $0 \mathrm{~K}$ and the non-temperature dependent linear expansion are assessed with this data while the reported melting curves $[47,50]$ allows to assess the bulk modulus at $0 \mathrm{~K}$. All the other parameters (temperature dependence of the thermal expansion, bulk modulus and pressure dependence of the bulk modulus and cut-off pressures) are kept fixed to the values found for $h c p$.

The results are presented in Figs. 2-3 and 6-7. For the melting curve, the agreement is very good up to at least $300 \mathrm{GPa}$. The refined bulk modulus is exactly the same as that of $h c p$ so that it exactly superimposes that of the $h c p$ phase in Fig. 4.

\section{2 metastable fcc Os and hcp Pt}

To model Os-Pt solid solutions, parameters are needed also for metastable phases such as $f c c$ Os and $h c p$ Pt. For this, obviously, we cannot rely on any experimental data. For this reason, we have calculated the pressure-volume dependence by DFT.

To avoid errors, instead of using directly the molar volume and the bulk modulus calculated by DFT, we preferred to use the difference between the calculated values for $f c c$ and $h c p$ phases and apply it to the optimized values for the stable phase to find those for the metastable ones.

For Os, we find $B_{f c c}-B_{h c p}=-9 \mathrm{GPa}$ and $V_{f c c}-V_{h c p}=0.03 \times 10^{-6} \mathrm{~m}^{3} / \mathrm{mol}$. This value is a good agreement with the (relatively scattered) reports from the literature $[37,41,43,45]$ (see a comparison in Supplementary Data).

For Pt, we find $B_{h c p}-B_{f c c}=-9 \mathrm{GPa}$ and $V_{h c p}-V_{f c c}=0.06 \times 10^{-6} \mathrm{~m}^{3} / \mathrm{mol}$. There are very few calculations of $h c p$ Pt available in the literature. Schönecker et al. report values for $V_{h c p}-V_{f c c}$ ranging from -2 to $8 \times 10^{-8} \mathrm{~m}^{3} / \mathrm{mol}$ depending on the calculation approximations used and the use or not of relativistic effects [56], non-negligible for $5 d$ elements, and a difference $B_{h c p}-B_{f c c}=-3.9 \mathrm{GPa}$ (S. Schönecker and $\mathrm{M}$. Richter, personal communication) in agreement with our value.

As far as the temperature dependence of the molar volume and the bulk modulus of the metastable phases of pure metals is concerned, the same variation as for the stable phases is assumed. Note that the assumptions made for the metastable phases do not influence very much the final calculation of the phase diagram.

\subsection{Os-Pt DFT calculations}

SQS calculations were used in order to obtain the enthalpy of mixing in the $f c c$ and $h c p$ binary solid solutions. The metastable $b c c$ phase was also calculated not to be included in the assessment but rather to serve as an estimate for the enthalpy of mixing in the liquid phase. Discrepancies are obtained for the energies of the SQS cells calculated with PBEsol functional. More consistent results are obtained with PBE and this functional was used for the energy calculations. The results are presented in Fig. 8. The enthalpies of mixing are all positive. 
In a second step, SQS calculation was done under pressure. This allowed to obtain important data such as volume as a function of composition at different pressures, as a function of pressure at different compositions, and the enthalpies of mixing as a function of composition at different pressures. As stated earlier for pure Os and in Part I of this article in the case of Pt, best results are obtained for the volume when calculated with PBEsol while the enthalpy of mixing was calculated using PBE. The volume is a linear function of composition and no deviation from the Vegard's law is observed at high pressure. Similarly, the enthalpy of mixing is shown to depend only marginally upon pressure.

\subsection{Os-Pt at ambient pressure}

The thermodynamic assessment was performed using the phase diagram data from Ref. [53] and the SQS enthalpies of mixing from the present work. This latter data was found necessary to fix the energy of the system that cannot be assessed from the limited phase diagram data only. We assumed that the enthalpy of mixing in the liquid phase was similar to that in the bcc phase. Given the scarcity of the available information on this system and the limited accuracy of the data of Ref. [53], we used as few parameters as possible. The results are shown in Figs. 8 and 9. The metastable phase diagram is also shown with the liquid phase suspended. This has an importance for the high pressure study because the liquid is destabilized at high pressure. It is shown that, according to the SGTE database, $f c c$ Os is stable over $h c p$ at $5200 \mathrm{~K}$. From this temperature and above a complete solid solution exists between Os and Pt in the $f c c$ phase. This is due to the lattice stability of $f c c \mathrm{Os}$ defined as GHSEROS+13000-2.5xT.

\section{5 extrapolation of Os-Pt system at high pressure}

Extrapolation of the Os-Pt system at high pressure was obtained by combining the description of the system at ambient pressure obtained in the previous section, the description of hcp and liquid Os obtained in Section 4.1, the description of $f c c$ and liquid Pt obtained in Part I of this article [11] and the values adopted in Section 4.2 for $f c c$ Os and $h c p$ Pt. No additional parameter was used. In particular, no excess term was used for the volume and the bulk modulus according to the observation of the Vegard's law at both low and high pressure in Section 4.3. A pressure dependence of the interaction parameters was neither used as justified by similar mixing enthalpies at ambient and high pressure. The phase diagram calculated for different pressures up to $500 \mathrm{GPa}$ is shown in Fig. 10. The molar volumes of the $h c p$ and $f c c$ phases are shown in Figs. 11 and 12 and compare very well with the available experimental data. The enthalpies of mixing are presented in Figs. 13 and 14 as a function of composition for different pressures.

\section{Discussion}

The description of systems at high pressure is very interesting and the Calphad method is very powerful to achieve this if proper models are used. Many pure elements in condensed phases are described in the literature with one or another model: $\mathrm{Mo}$ [57], $\mathrm{Mn}$ and $\mathrm{Ni}$ [58], $\mathrm{Cu}$ [59], $\mathrm{Al}$ and $\mathrm{Fe}$ [60], $\mathrm{Ag}, \mathrm{Au}, \mathrm{Cu}, \mathrm{Mo}, \mathrm{Nb}, \mathrm{Pd}, \mathrm{Pt}, \mathrm{Ta}, \mathrm{V}$ and $\mathrm{W}$ [61], $\mathrm{Hf}$ [62], Al and Pt [63], $\mathrm{Cu}$ and $\mathrm{Zn}$ [64], Al and Si [65], Ni [66], Pt [67]. Much fewer descriptions of binary or higher order systems are available: $\mathrm{Mn}-\mathrm{Ni}$ [58], C-Fe [68], Al-Si [65], H-Ni [66], Al-Cu-Mg [69], Bi-Sb, Bi-Sn and Pb-Sn [70]. Calphad modeling of phase diagrams under pressure might minimize experimental efforts and speed up further 
development of pressure dependent phase diagrams investigation. Compared to high-temperature research, high-pressure studies require more experimental work with access to large research infrastructure. Due to high costs of high-pressure research, experimental studies are quite limited and should be supported by precise modeling based on reliable models.

The originality of our approach, apart from using Lu's (2005) model corrected in Part I of this paper, consists in the DFT calculation of the excess energetic and volume terms under pressure. Based on this, the use of pressure dependent binary parameters, for the present system, was found unnecessary. It was not possible to use the treatment of Emuna et al. [70] due to the lack of sound velocity and density data for the solutions. Our finding that no pressure dependence of the excess term is necessary may be related to the absence of any excess volume as stated by Makov et al. [71].

Concerning the description of pure Os, the same comments as made for Pt in Part I of this paper can be done. With the corrections brought to the Lu's model, we avoid the unconsidered decrease of the $C_{p}$ as a function of pressure as shown in Fig. 15. However, there are several problems with the SGTE description for this element. First, there is an unconsidered variation of the $C_{p}$ at high temperature due to the absence for this element (as well as for platinum) of the SGTE extrapolation for the $C_{p}$. The $C_{p}$ of the $h c p$ phase gets negative above $8000 \mathrm{~K}$ but this is not coming from the model and this already occurs at low pressure. Second, the lattice stability of the $f c c$ phase is poorly optimized making this phase stable above $5200 \mathrm{~K}$ without any reason.

Very recently, experiments were conducted allowing to investigate Os-Pt phase diagram up to $50 \mathrm{GPa}$ [9]. The main finding is the absence of significant changes of the mutual solubilities with pressure. This is absolutely confirmed by the present calculations. For Os-Pt system, the general prediction made in previous literature [4] of a displacement of the two-phase domain towards the element with higher volume is not verified. On the contrary, we observe a small symmetric narrowing of the two-phase domain, but this only at extreme pressures above $100 \mathrm{GPa}$.

This testifies for the reliability of Lu's model to combine systems within the Calphad approach. The numerous advantages of this model have been summarized in Part I of the present paper [11]. Together with Brosh's (2007) model [72], it is one of the only approach allowing extrapolation to multicomponents with full description of the systems (including liquid and pure elements in metastable structures). Comments on these two different models have been given in Part I.

Given the remaining anomalies and approximation of the model, the uncertainties on the experiments on which the model is optimized and the lack of data in certain pressure and temperature ranges, we believe that Fig. 10 represents well the temperature and pressure ranges in which predictions may be trusted i.e. up to $6000 \mathrm{~K}$ and $500 \mathrm{GPa}$.

\section{Conclusion}

Os single component system has been completely described using a modified version of Lu's (2005) model. The Os-Pt binary system was successfully described using a combination of the unary descriptions at high pressure and temperature with estimate of the metastable phases and the low pressure description of the binary system. Reasonable agreement is obtained with experimental data recently obtained. The modified Lu's model is shown to extrapolate very well to binary systems. This opens a new possibility to extend high pressure descriptions to binary and multi-component systems and predict their pressure-temperature-dependent phase diagrams. 


\section{Acknowledgments}

DFT and phonon calculations were performed using HPC resources from GENCl-CINES (Grant A0080906175). Guillaume Deffrennes is deeply acknowledged for the fruitful discussions we had, in particular during the revision of this article. 
Table 1: summary of relevant data for the optimization of osmium (D(WC)AC: Diamond (Tungsten carbide) Anvil Cell, (S)XRD: (Synchrotron) X-Ray Diffraction).

\begin{tabular}{|c|c|c|c|c|}
\hline Phase & Data type & Range & Reference & $\begin{array}{l}\text { Experimental and/or } \\
\text { modeling } \\
\text { techniques }\end{array}$ \\
\hline \multirow[t]{17}{*}{$h c p$} & $\begin{array}{l}V-T \\
\text { at } p=10^{5} \mathrm{~Pa}\end{array}$ & $0-1300 \mathrm{~K}$ & {$[27]$} & $\begin{array}{l}\text { assessment of } \\
\text { experimental data }\end{array}$ \\
\hline & $\begin{array}{l}\alpha-T \\
\text { at } p=10^{5} \mathrm{~Pa}\end{array}$ & $0-1300 \mathrm{~K}$ & {$[27]$} & $\begin{array}{l}\text { assessment of } \\
\text { experimental data }\end{array}$ \\
\hline & $V-p$ & $0-65 \mathrm{GPa}$ & [29] & DAC SXRD \\
\hline & at $300 \mathrm{~K}$ & & & \\
\hline & & $0-58 \mathrm{GPa}$ & {$[30]$} & DAC SXRD \\
\hline & & 0-75 GPa & [31] & DAC SXRD \\
\hline & & 0-13 GPa & [32] & WCAC SXRD \\
\hline & & $0-50 \mathrm{GPa}$ & [33] & DAC SXRD \\
\hline & & $0-64 \mathrm{GPa}$ & [34] & DAC SXRD \\
\hline & & 0-750 GPa & {$[25]$} & DAC SXRD \\
\hline & & 0-207 GPa & {$[35]$} & DAC SXRD \\
\hline & $B-T$ & $0-300 \mathrm{~K}$ & {$[36]$} & Sound velocity \\
\hline & $V-T-p$ & $0-13 \mathrm{GPa}$ & {$[32]$} & WCAC SXRD \\
\hline & & $300-1273 \mathrm{~K}$ & & \\
\hline & & $0-50 \mathrm{GPa}$ & [33] & DAC SXRD \\
\hline & & $300-3000 \mathrm{~K}$ & & \\
\hline & Hugoniot & $0-800 \mathrm{GPa}$ & [39] & DFT calculation \\
\hline \multirow[t]{3}{*}{ liquid } & $V-T$ & $\begin{array}{l}2677 \\
\text { (undercooled)- } \\
3347 \mathrm{~K}\end{array}$ & [51] & imaging, levitation \\
\hline & $T_{m}-p$ & $0-500 \mathrm{GPa}$ & {$[47]$} & $a b$ initio $\mathrm{Z}$ method \\
\hline & & $0-35 \mathrm{GPa}$ & {$[50]$} & DAC SXRD \\
\hline
\end{tabular}


Table 2: available DFT calculation for Os.

\begin{tabular}{|c|c|c|c|c|c|}
\hline Phase & Calculated property & Range & Reference & $\begin{array}{l}\text { Calculation } \\
\text { technique }\end{array}$ & $\begin{array}{l}\mathrm{XC} \\
\text { functional }\end{array}$ \\
\hline $\begin{array}{l}h c p, \\
f c c\end{array}$ & $B$ & $0 \mathrm{~K}$ & [37] & $\begin{array}{l}\text { relativistic } \\
\text { FP-LAPW }\end{array}$ & LDA,GGA \\
\hline$h c p$ & $V-p, B-p$ & $0-100 \mathrm{GPa}$ & {$[38]$} & PP-PAW & GGA-PBE \\
\hline$h c p$ & $\begin{array}{l}V-p, T_{m}-p \\
\text { (Lindeman), } \\
\text { Hugoniot }\end{array}$ & $0,300 \mathrm{~K}, 0-700 \mathrm{GPa}$ & [39] & FP-LAPW & GGA \\
\hline$h c p$ & $\begin{array}{l}V-T-p \\
B-T-p \\
\alpha-T-p\end{array}$ & $\begin{array}{l}0-2000 \mathrm{~K} \\
0-250 \mathrm{GPa}\end{array}$ & {$[40]$} & $\begin{array}{l}\text { PP-PAW } \\
\text { QHA }\end{array}$ & LDA, GGA \\
\hline $\begin{array}{l}h c p, \\
f c c\end{array}$ & $\begin{array}{l}B-T \\
\alpha-T \\
V-p\end{array}$ & $\begin{array}{l}0-300 \mathrm{~K} \\
0,50,100 \mathrm{GPa}, 0-3500 \mathrm{~K} \\
300,2400 \mathrm{~K}, 0-100 \mathrm{GPa}\end{array}$ & [41] & $\begin{array}{l}\text { PP-USPP } \\
\text { QHA }\end{array}$ & LDA+U \\
\hline$h c p$ & $\begin{array}{l}V-p \\
\alpha-T-p\end{array}$ & $\begin{array}{l}0-60 \mathrm{GPa} \\
0-1200 \mathrm{~K}, 0-60 \mathrm{GPa}\end{array}$ & {$[42]$} & PP-PAW & GGA-PBE \\
\hline $\begin{array}{l}h c p, \\
f c c\end{array}$ & $\begin{array}{l}V-p \\
\alpha-T-p \\
C_{v}-T-p\end{array}$ & $\begin{array}{l}0-60 \mathrm{GPa} \\
0-3000 \mathrm{~K}, 0-60 \mathrm{GPa} \\
0-3000 \mathrm{~K}, 0-60 \mathrm{GPa}\end{array}$ & [43] & $\begin{array}{l}\text { PP-USPP } \\
\text { QHA }\end{array}$ & $\begin{array}{l}\text { LDA, } \\
\text { GGA-PBE }\end{array}$ \\
\hline$h c p$ & $\begin{array}{l}V-p \\
\alpha-T-p \\
B-T-p \\
C_{p}-T-p\end{array}$ & $\begin{array}{l}300,2000,3000 \mathrm{~K}, 0- \\
170 \mathrm{GPa} \\
0-3000 \mathrm{~K}, 0-300 \mathrm{GPa} \\
0-3000 \mathrm{~K}, 0-300 \mathrm{GPa} \\
0-3000 \mathrm{~K}, 0-300 \mathrm{GPa}\end{array}$ & {$[44]$} & $\begin{array}{l}\text { FP-USPP } \\
\text { QHA }\end{array}$ & GGA-PBE \\
\hline $\begin{array}{l}h c p, \\
f c c, \\
b c c, \\
\omega\end{array}$ & $\begin{array}{l}\text { stability- } p \\
B, B^{\prime}\end{array}$ & $0-400 \mathrm{GPa}$ & {$[45]$} & FP-LAPW & GGA-PBE \\
\hline$h c p$ & $V-p$ & 0-900 GPa & {$[47]$} & PP-PAW & GGA-PBE \\
\hline$h c p$ & $V-p$ & $0-600 \mathrm{GPa}$ & {$[25]$} & FP-LAPW & LDA, GGA \\
\hline$h c p$ & $B$ & & [46] & PP-USPP & LDA \\
\hline$h c p$ & $\begin{array}{l}V-p \\
a, c, V-T \\
\alpha-T\end{array}$ & $\begin{array}{l}300 \mathrm{~K}, 0-20 \mathrm{GPa} \\
0-2000 \mathrm{~K} \\
0-2000 \mathrm{~K}\end{array}$ & {$[21]$} & $\begin{array}{l}\text { PP-PAW } \\
\text { QHA }\end{array}$ & $\begin{array}{l}\text { LDA, PBE, } \\
\text { PBEsol }\end{array}$ \\
\hline
\end{tabular}


Table 3: Calphad model parameters.

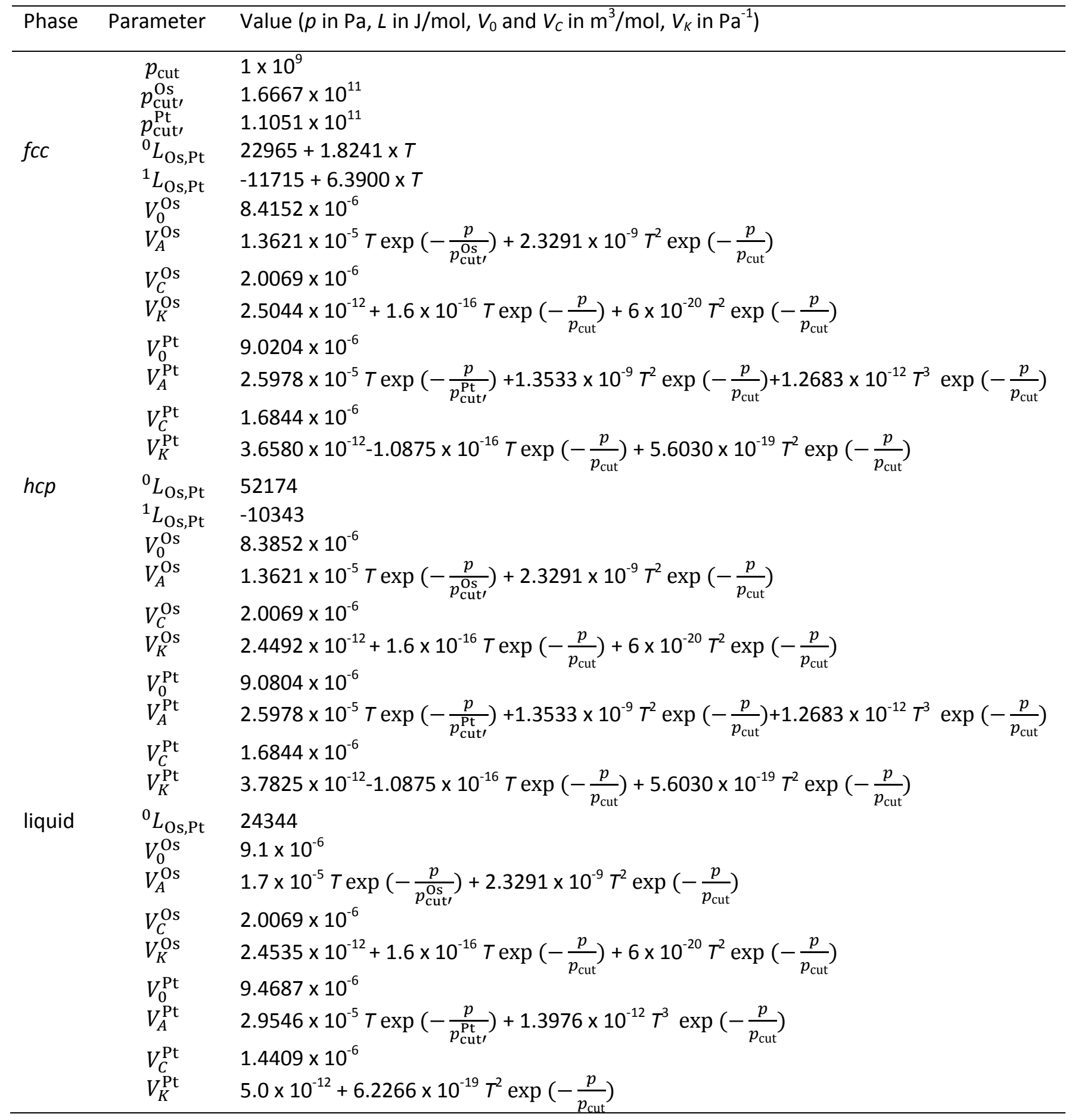




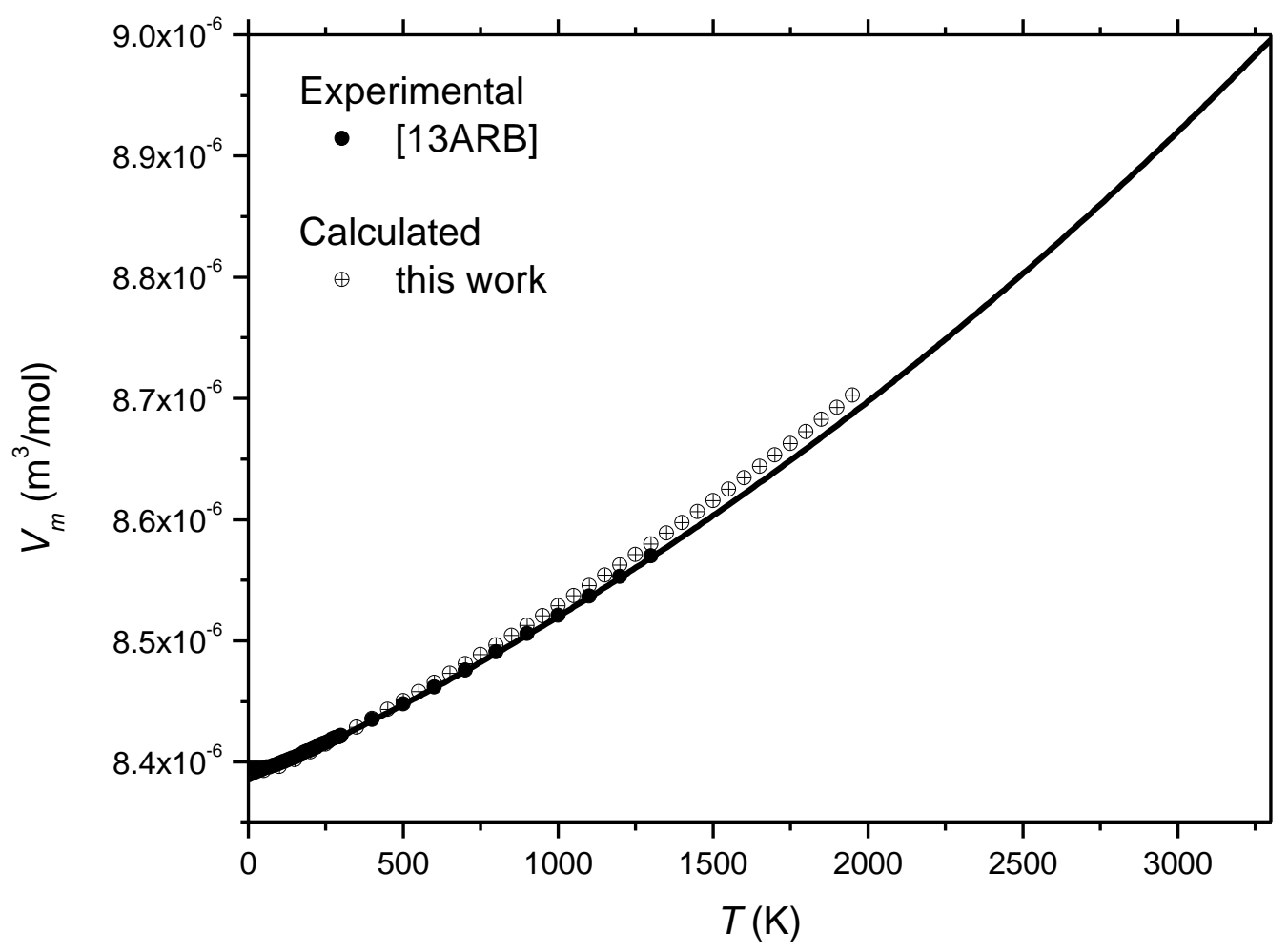

Figure 1: Molar volume of $h c p$ Os as a function of temperature. The experimental data is from Ref. [27] [13ARB]. Calculated data are obtained in this work from PBEsol DFT and phonon calculation at zero pressure. 

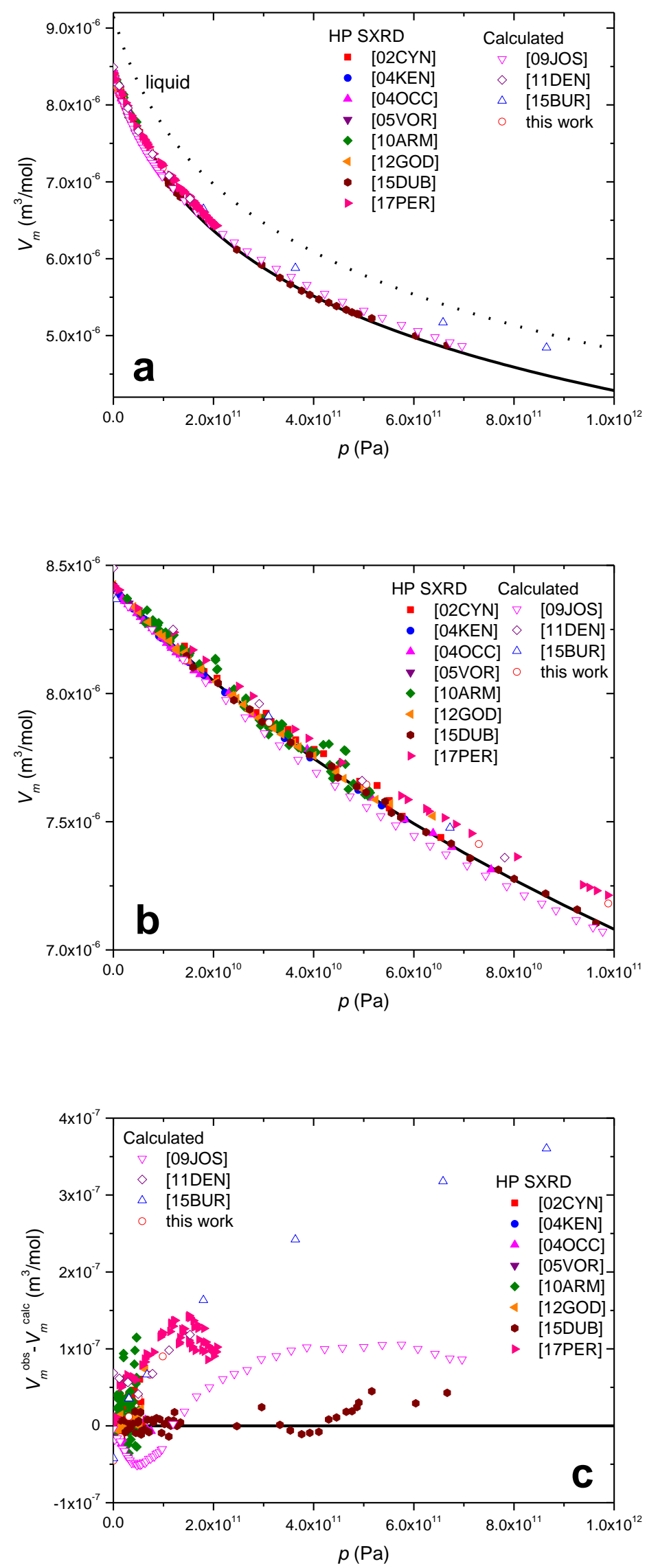


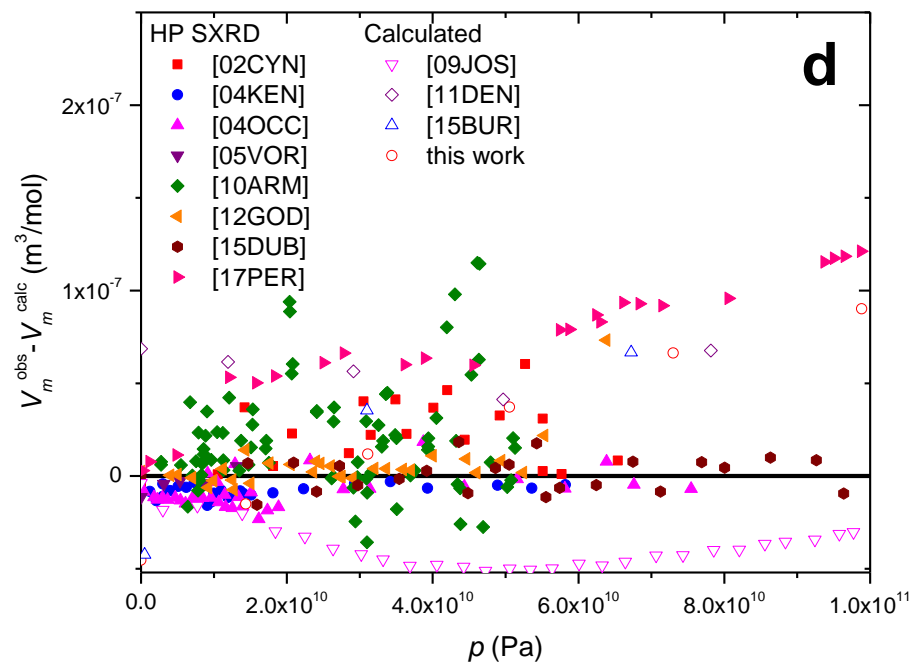

Figure 2: Molar volume of $h c p$ Os as a function of pressure at $300 \mathrm{~K}$ (full scale with the liquid phase (a) and lower pressure region (b)) and difference between observed and calculated volume (full scale (c) and lower pressure region (d)). The experimental data are from Refs. [29] [02CYN], [30] [04KEN], [31] [04OCC], [32] [05VOR], [33] [10ARM], [34] [12GOD], [25] [15DUB], [35] [17PER]. The calculated data are from Refs. [39] [09JOS], [44] [11DEN], [47] [15BUR] and obtained in this work from PBEsol calculation.

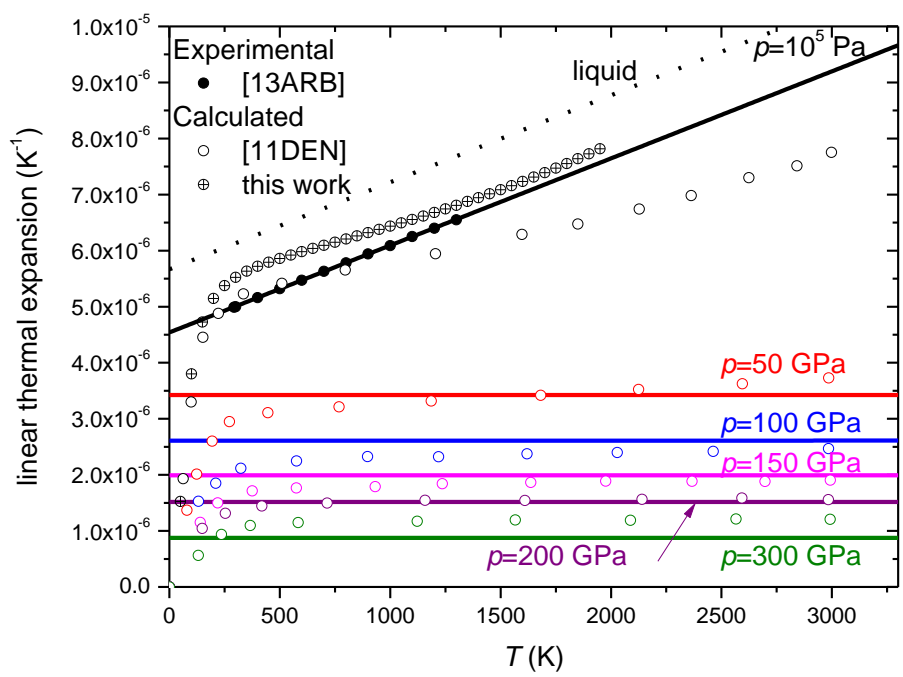

Figure 3: Linear thermal expansion of $h c p$ Os as a function of temperature for different pressures. Liquid Os is also shown at $p=10^{5} \mathrm{~Pa}$. The experimental data is from Refs. [27] [13ARB]. The calculated data are from Ref. [44] [11DEN] and obtained in this work from PBEsol DFT and phonon calculation at zero pressure. 


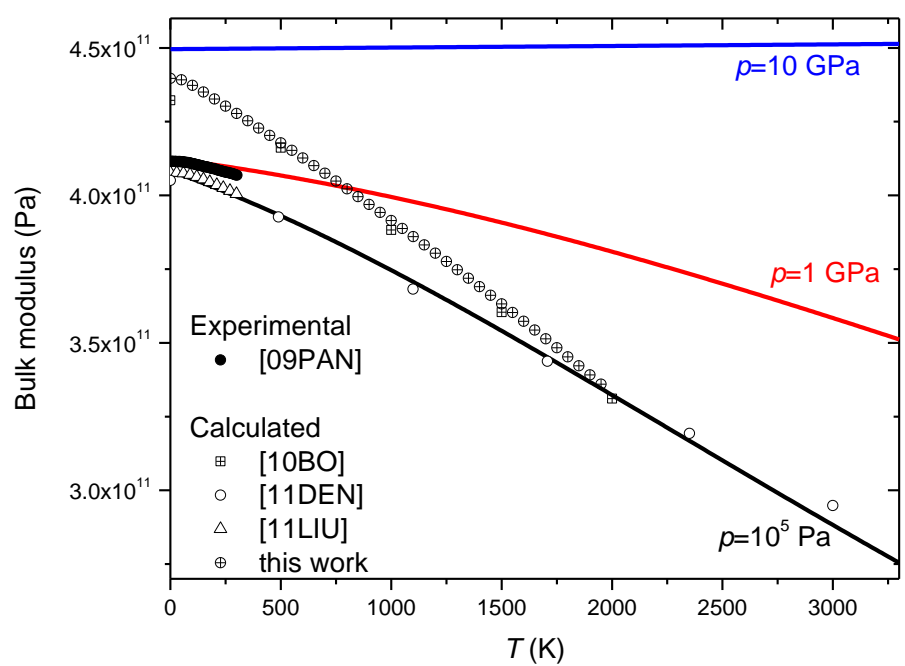

Figure 4: Bulk modulus of $h c p$ Os as a function of temperature at different pressures. The experimental data is from Ref. [36] [09PAN]. The calculated data at zero pressure are from Refs. [40] [10BO], [44] [11DEN] and [41] [11LIU] and obtained in this work from PBEsol DFT and phonon calculation. The calculated bulk modulus of liquid Os exactly superimposes that of the $h c p$ phase.

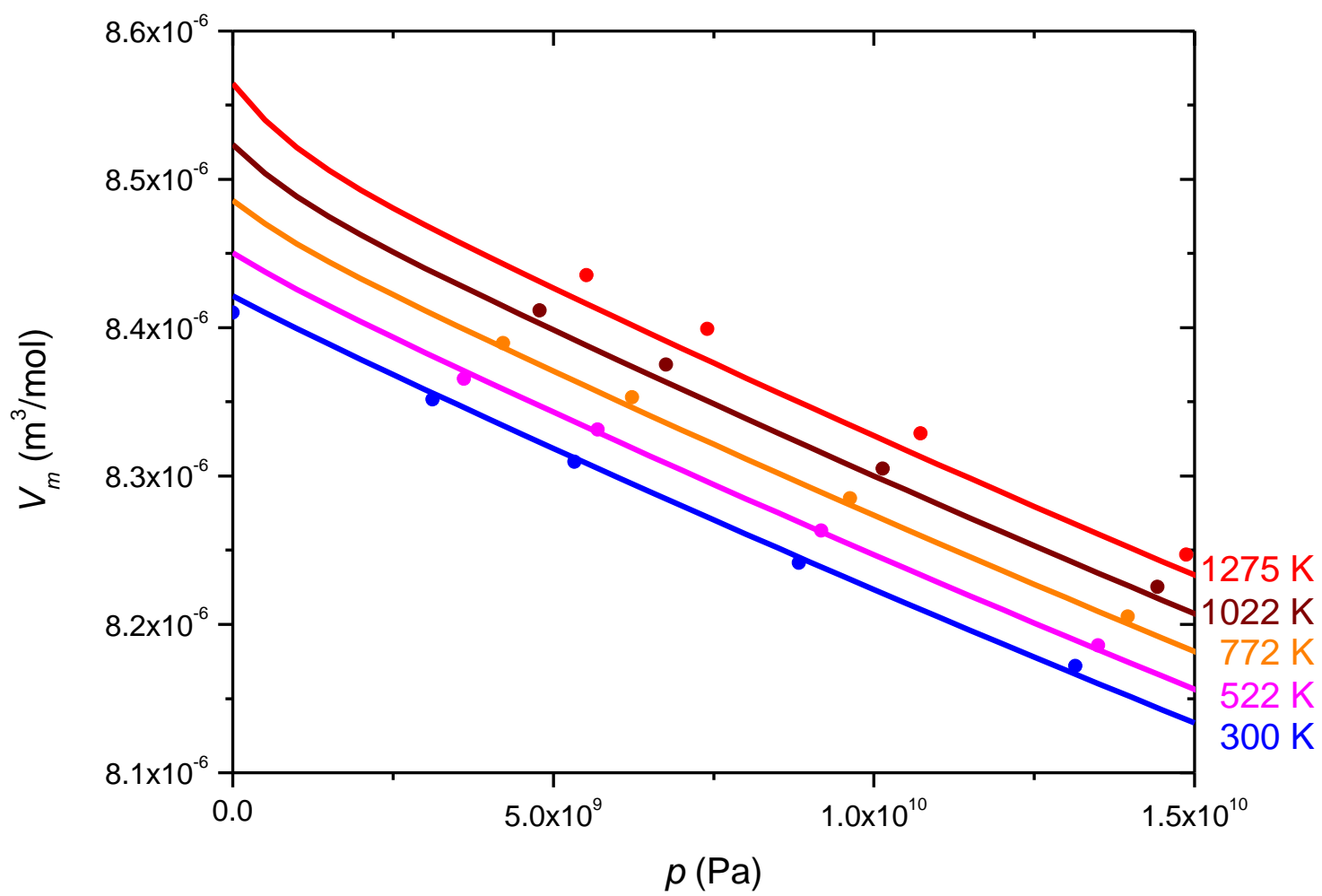

Figure 5: Molar volume of $h c p$ Os as a function of pressure at different temperatures. Experimental data is from Ref. [32]. 


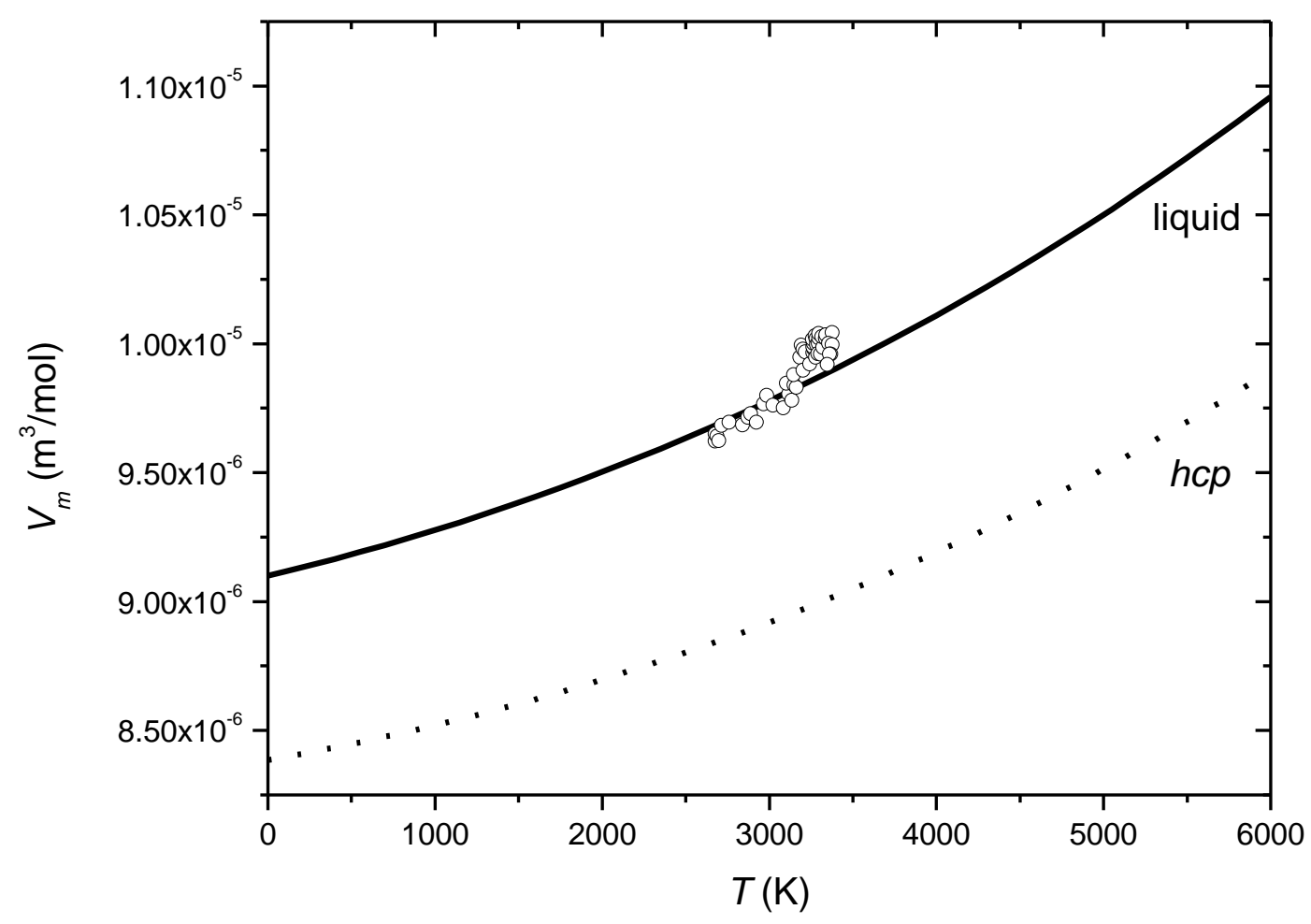

Figure 6: Molar volume of liquid Os at $p=10^{5} \mathrm{~Pa}$ ( $h c p$ is shown for comparison). The experimental data is from Ref. [51].

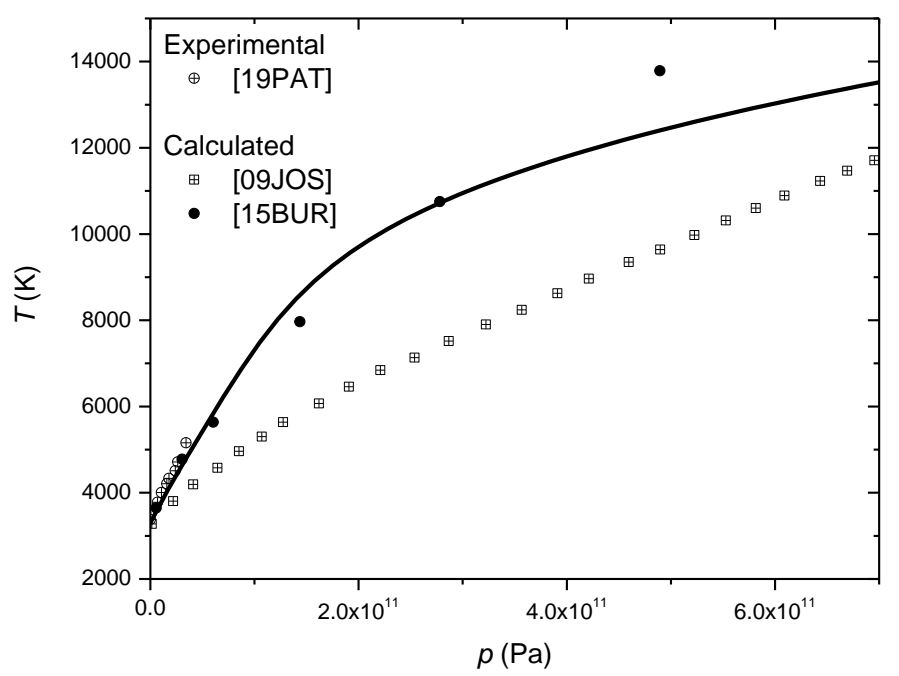

Figure 7: melting curve of Os. The experimental data is from Ref. [50] [19PAT]. The calculated data are from Refs. [39] [09JOS] and [47] [15BUR]. 


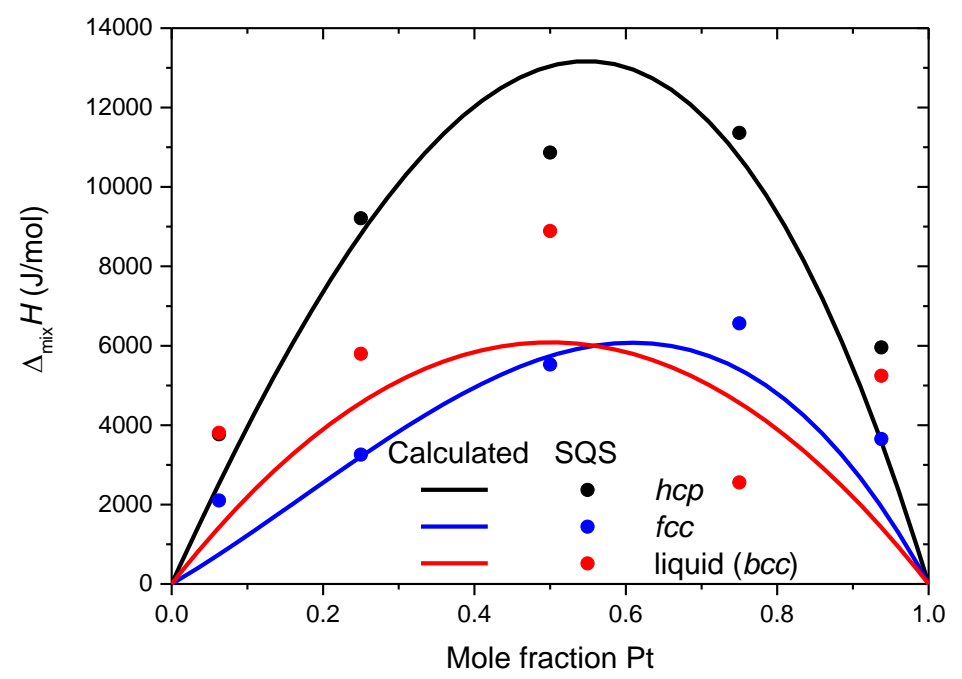

Figure 8: Enthalpies of mixing in the $h c p, f c c$ and the liquid phases at ambient pressure (independent of temperature). The SQS calculation (at $0 \mathrm{~K}$ ) is from this work. For the liquid phase, the SQS calculation shown is that of the bcc phase.

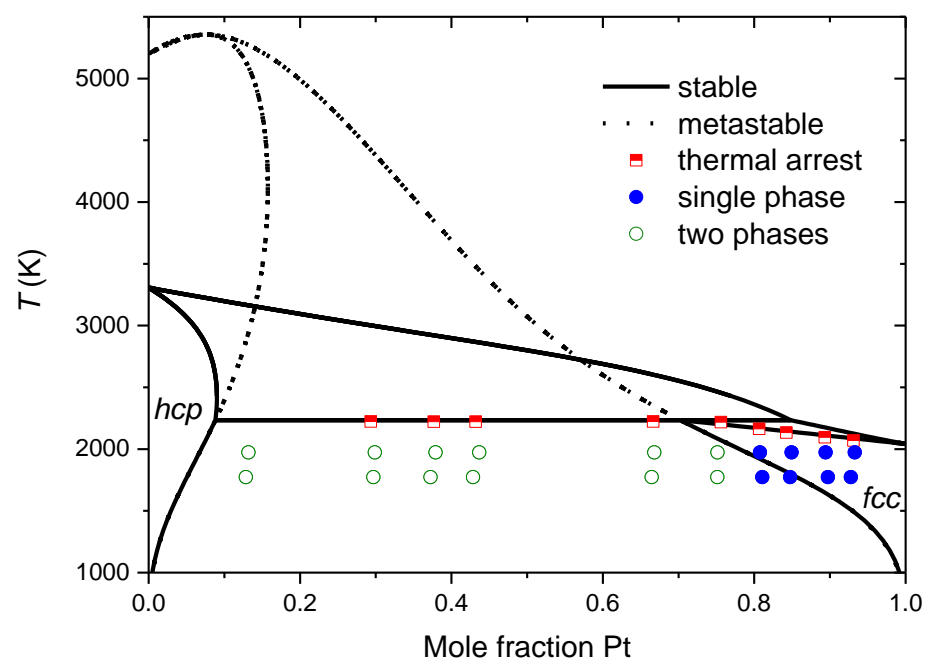

Figure 9: Calculated phase diagram of the Os-Pt system at ambient pressure. Both stable and metastable (obtained by suspending the liquid phase) phase diagrams are shown. The experimental data is from Ref. [53]. 


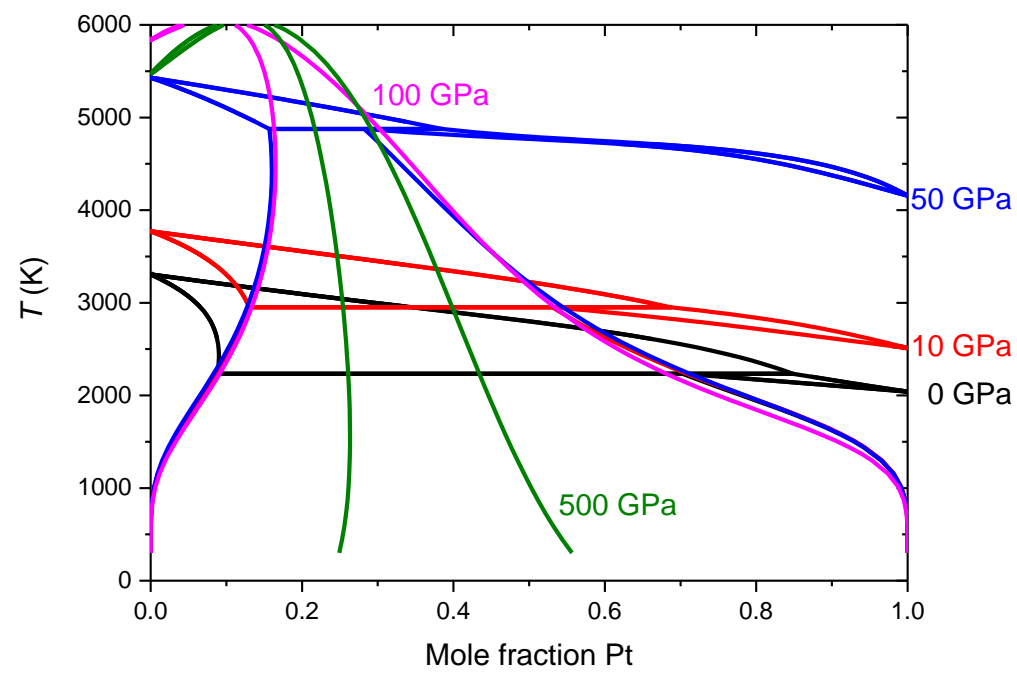

Figure 10: Calculated phase diagram of the Os-Pt system at different pressures as indicated.

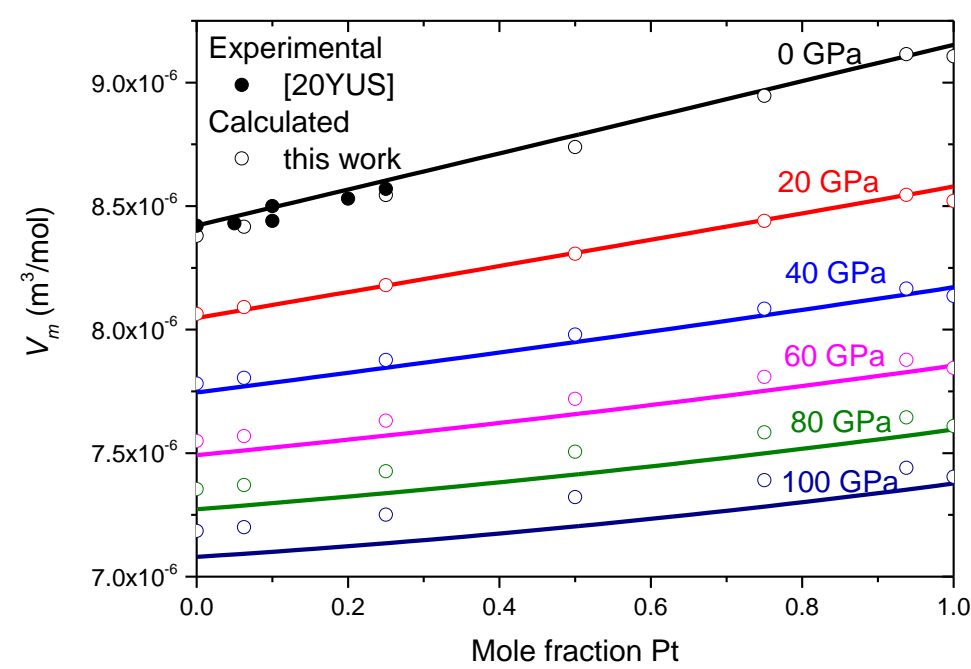

Figure 11: Molar volume of the hcp Os-Pt solid solution as a function of composition at $300 \mathrm{~K}$ and at different pressures. The experimental data at ambient pressure (300 K) is from Ref. [9] [20YUS]. The calculated data is obtained in this work from the compression of SQS cells $(0 \mathrm{~K})$. 


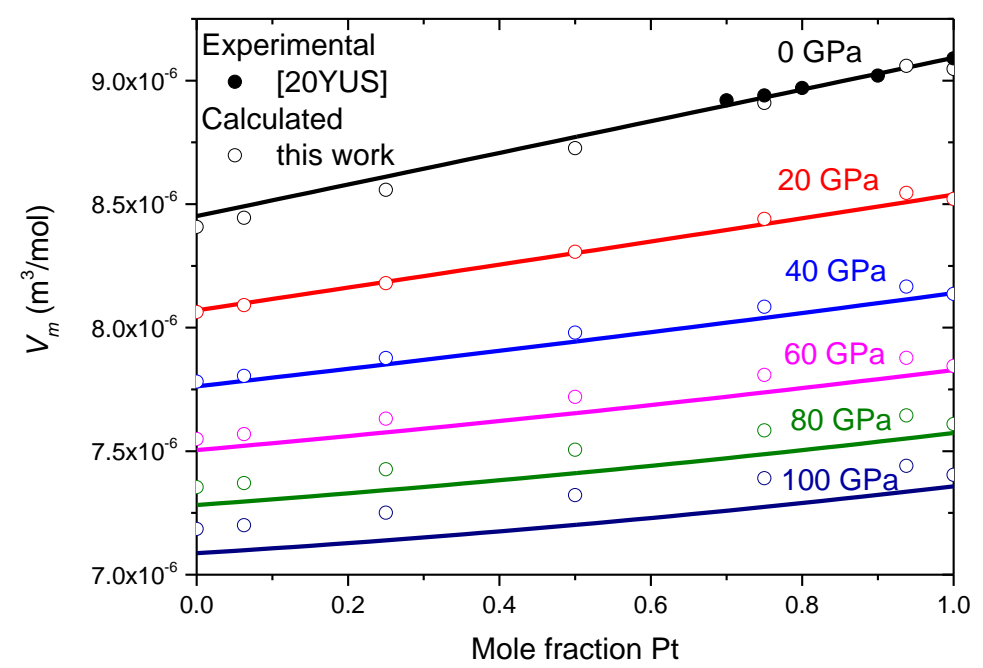

Figure 12: Molar volume of the $f c c$ Os-Pt solid solution as a function of composition at $300 \mathrm{~K}$ at different pressures. The experimental data at ambient pressure (300 K) is from Ref. [9] [20YUS]. The calculated data is obtained in this work from the compression of SQS cells $(0 \mathrm{~K})$.

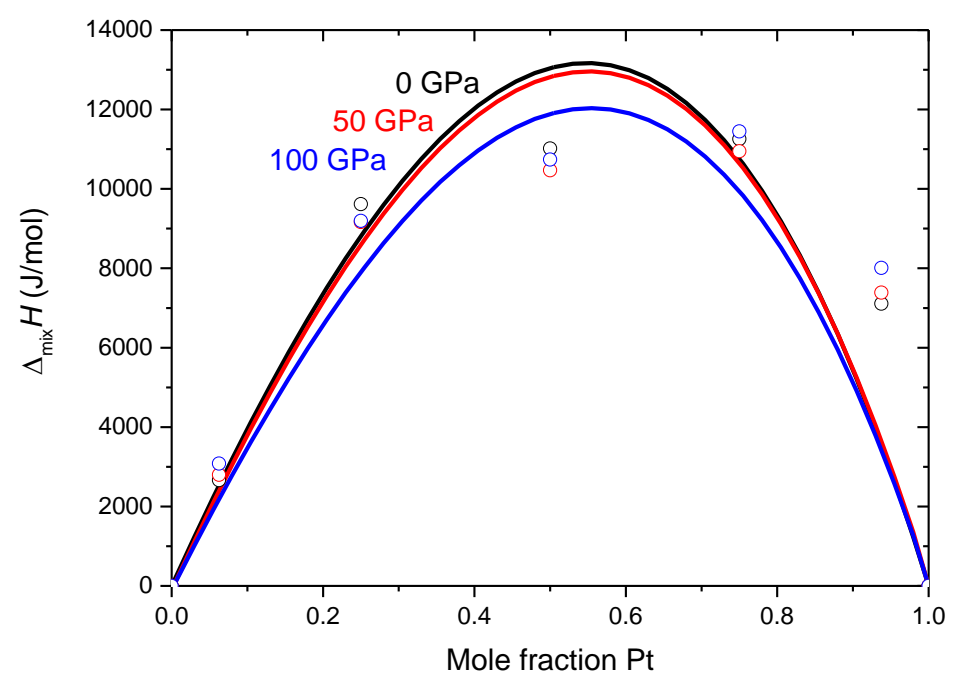

Figure 13: Enthalpy of mixing in the hcp Os-Pt solid solution as a function of composition at different pressures (independent of temperature). The calculated data is obtained in this work from the compression of SQS cells (O K). 


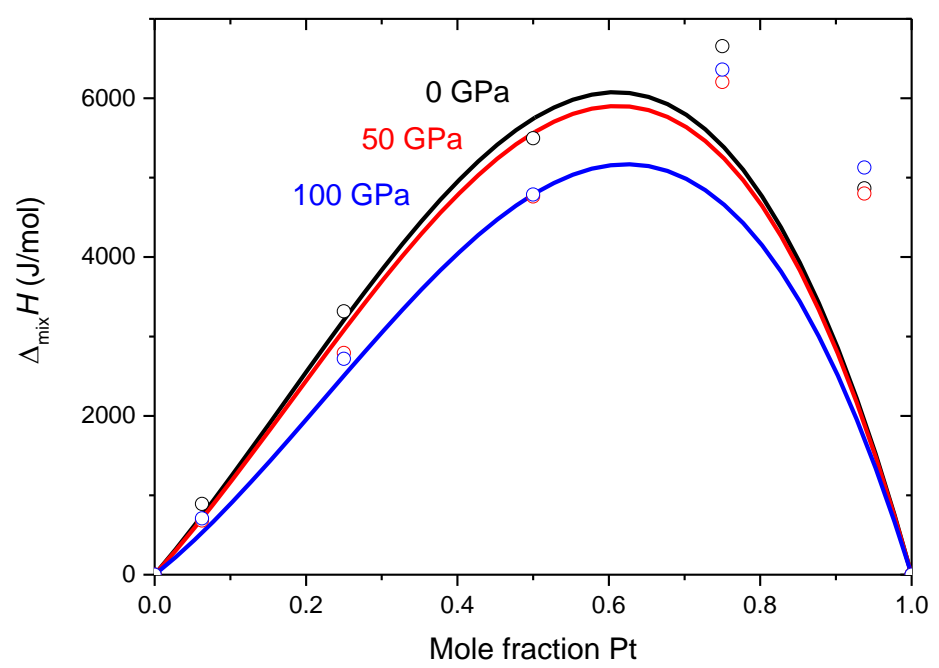

Figure 14: Enthalpy of mixing in the fcc Os-Pt solid solution as a function of composition at different pressures (independent of temperature). The calculated data is obtained in this work from the compression of SQS cells (0 K).

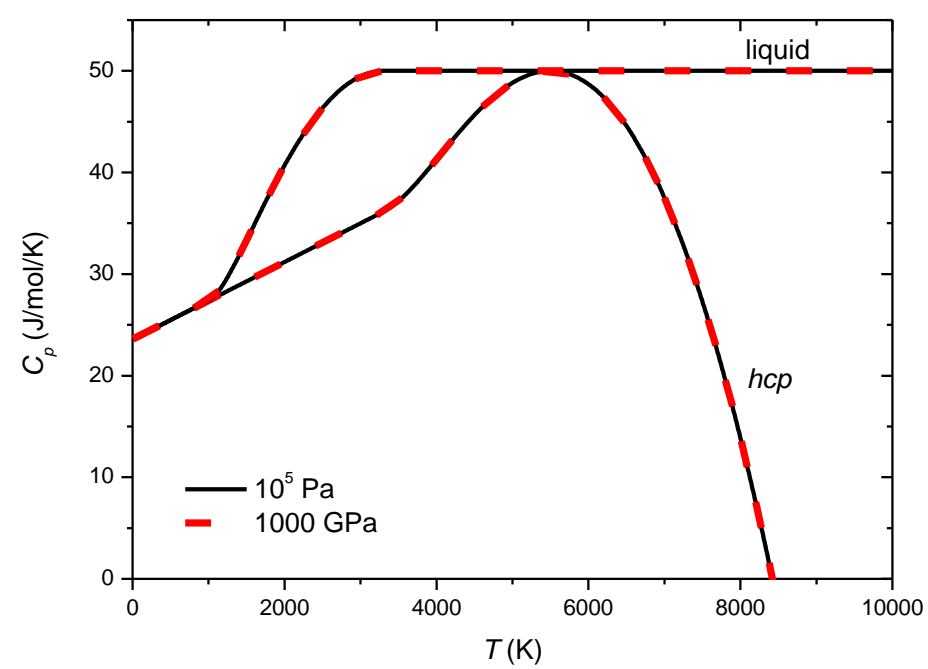

Figure 15: $C_{p}$ of $h c p$ and liquid Os as a function of temperature at ambient and at high pressure. 
[1] R. Liu, H. Iddir, Q. Fan, G. Hou, A. Bo, K.L. Ley, E.S. Smotkin, Y.-E. Sung, H. Kim, S. Thomas, A. Wieckowski, Potential-dependent infrared absorption spectroscopy of adsorbed $\mathrm{CO}$ and $\mathrm{X}$ ray photoelectron spectroscopy of arc-melted single-phase Pt, PtRu, PtOs, PtRuOs, and Ru electrodes, J. Phys. Chem. B 104 (15) (2000) 3518-3531.

[2] H.-C. Tsai, Y.-C. Hsieh, T.H. Yu, Y.-J. Lee, Y.-H. Wu, B.V. Merinov, P.-W. Wu, S.-Y. Chen, R.R. Adzic, W.A. Goddard III, DFT study of oxygen reduction reaction on Os/Pt core-shell catalysts validated by electrochemical experiment, ACS Catal. 5 (3) (2015) 1568-1580.

[3] N. Dimakis, F.A. Flor, N.E. Navarro, A. Salgado, E.S. Smotkin, Adsorption of carbon monoxide on platinum-ruthenium, platinum-osmium, platinum-ruthenium-osmium, and platinumruthenium-osmium-iridium alloys, J. Phys. Chem. C 120 (19) (2016) 10427-10441.

[4] R.O.C. Fonseca, V. Laurenz, G. Mallmann, A. Luguet, N. Hoehne, K.P. Jochum, New constraints on the genesis and long-term stability of Os-rich alloys in the Earth's mantle, Geochim. Cosmochim. Acta 87 (2012) 227-242.

[5] K.V. Yusenko, E. Bykova, M. Bykov, S.A. Gromilov, A.V. Kurnosov, C. Prescher, V.B. Prakapenka, M. Hanfland, S. van Smaalen, S. Margadonna, L.S. Dubrovinsky, Compressibility of Ir-Os alloys under high pressure, J. Alloys Compd. 622 (2015) 155-161.

[6] K.V. Yusenko, E. Bykova, M. Bykov, S. Riva, W.A. Crichton, M.V. Yusenko, A.S. Sukhikh, S. Arnaboldi, M. Hanfland, L.S. Dubrovinsky, S.A. Gromilov, Ir-Re binary alloys under extreme conditions and their electrocatalytic activity in methanol oxydation, Acta Mater. 139 (2017) 236-243.

[7] K.V. Yusenko, E. Bykova, M. Bykov, S.A. Gromilov, A.V. Kurnosov, C. Prescher, V.B. Prakapenka, W.A. Crichton, M. Hanfland, S. Margadonna, L.S. Dubrovinsky, High-pressure high-temperature stability of $h c p-\mathrm{Ir}_{\mathrm{x}} \mathrm{Os}_{1-\mathrm{x}}(\mathrm{x}=0.50$ and 0.55$)$ alloys, J. Alloys Compd. 700 (2017) 198-207.

[8] K.V. Yusenko, S. Khandarkhaeva, T. Fedotenko, A. Pakhomova, S.A. Gromilov, L. Dubrovinsky, N. Dubrovinskaya, Equations of state of rhodium, iridium and their alloys up to $70 \mathrm{GPa}$, J. Alloys Compd. 788 (2019) 212-218.

[9] K.V. Yusenko, K. Spektor, S. Khandarkhaeva, T. Fedotenko, A. Pakhomova, I. Kupenko, A. Rorhbach, S. Klemme, W.A. Crichton, T.V. Dyachkova, A.P. Tyutyunnik, Y.G. Zainulin, L.S. Dubrovinsky, S.A. Gromilov, Decomposition of single-source precursors under hightemperature high-pressure to access osmium-platinum refractory alloys, J. Alloys Compd. $813(2020) 152121$

[10] X.-G. Lu, M. Selleby, B. Sundman, Implementation of a new model for pressure dependence of condensed phases in Thermo-Calc, Comput. Coupling Phase Diagr. Thermochem. 29 (2005) 49-55.

[11] J.-M. Joubert, J.-C. Crivello, G. Deffrennes, Modification of Lu's (2005) high pressure model for improved high pressure/high temperature extrapolations. Part I: modeling of platinum at high pressure/high temperature, Calphad: Comput. Coupling Phase Diagrams Thermochem. submitted (2021).

[12] G. Kresse, J. Furthmüller, Efficient iterative schemes for ab initio total-energy calculations using a plane-wave basis set, Phys. Rev., B 54 (1996) 11169-11186. https://doi.org/10.1103/PhysRevB.54.11169.

[13] G. Kresse, D. Joubert, From ultrasoft pseudopotentials to the projector augmented-wave method, Phys. Rev., B 59 (3) (1999) 1758-1775. https://doi.org/10.1103/PhysRevB.59.1758.

[14] P.E. Blöchl, Projector augmented-wave method, Phys. Rev., B 50 (24) (1994) 17953-17979. 
[15] J.P. Perdew, A. Zunger, Self-interaction correction to density-functional approximations for many-electron systems, Phys. Rev. B23 (1981) 5048-5079.

[16] J.P. Perdew, K. Burke, M. Ernzerhof, Generalized gradient approximation made simple, Phys. Rev. Lett. 77 (18) (1996) 3865-3868. https://doi.org/10.1103/PhysRevLett.77.3865.

[17] G.I. Csonka, J.P. Perdew, A. Ruzsinszky, P.H.T. Philipsen, S. Lebègue, J. Paier, O.A. Vydrov, J.G. Angyan, Assessing the performance of recent density functionals for bulk solids, Phys. Rev. B79 (2009) 155107.

[18] H.J. Monkhorst, J.D. Pack, Special points for Brillouin-zone integrations, Phys. Rev., B 13 (1976) 5188-5192.

[19] K. Parlinski, Z.Q. Li, Y. Kawazoe, First-principles determination of the soft mode in cubic $\mathrm{ZrO}_{2}$, Phys. Rev. Lett. 78 (1997) 4063-4066.

[20] A. Togo, I. Tanaka, First principles phonon calculations in materials science, Scr. Mater. 108 (2015) 1-5.

[21] M. Palumbo, A. Dal Corso, Lattice dynamics and thermophysical properties of h.c.p. Os and Ru from the quasi-harmonic approximation, J. Phys., Condens. Matter. 29 (39) (2017) 395401.

[22] A. Zunger, S.-H. Wei, L.G. Ferreira, J.E. Bernard, Special quasirandom structures, Phys. Rev. Lett. 65 (3) (1990) 353-356.

[23] C. Wolverton, Crystal structure and stability of complex precipitate phases in Al-Cu-Mg-(Si) and Al-Zn-Mg alloys, Acta Mater. 49 (2001) 3129-3142.

[24] D. Shin, R. Arróyave, Z.-K. Liu, A. Van de Walle, Thermodynamic properties of binary hcp solution phases from special quasirandom structures, Phys. Rev. B74 (2006) 024204.

[25] L. Dubrovinsky, N. Dubrovinskaya, E. Bykova, M. Bykov, V. Prakapenka, C. Prescher, K. Glazyrin, H.-P. Liermann, M. Hanfland, M. Ekholm, L.V. Pourovskii, M.I. Katsnelson, J.M. Wills, I.A. Abrikosov, The most incompressible metal osmium at static pressures above 750 gigapascals, Nature 525 (September) (2015) 226-229.

[26] J.W. Arblaster, Is osmium aways the densest metal?, Jonhson Matthey Tech. 58 (3) (2014) 137-141.

[27] J.W. Arblaster, Crystallographic properties of osmium, Platin. Met. Rev. 57 (3) (2013) 177185.

[28] J.W. Arblaster, A re-assessment of the thermodynamic properties of osmium. Improved value for the enthalpy of fusion, Jonhson Matthey Tech. 65 (1) (2021) 54-63.

[29] H. Cynn, J.E. Klepeis, C.-S. Yoo, D.A. Young, Osmium has the lowest experimentally determined compressibility, Phys. Rev. Lett. 88 (13) (2002) 135701.

[30] T. Kenichi, Bulk modulus of osmium: high-pressure powder X-ray diffraction experiments under quasihydrostatic conditions, Phys. Rev. B70 (2004) 012101.

[31] F. Occelli, D.L. Farber, J. Badro, C.M. Aracne, D.M. Teter, M. Hanfland, B. Canny, B. Couzinet, Experimental evidence for a high-pressure isostructural phase transition in osmium, Phys. Rev. Lett. 93 (9) (2004) 095502.

[32] G.A. Voronin, C. Pantea, T.W. Zerda, L. Wang, Y. Zhao, Thermal equation-of-state of osmium: a synchrotron X-ray diffraction study, J. Phys. Chem. Solids 66 (2005) 706-710.

[33] M.M. Armentrout, A. Kavner, Incompressibility of osmium metal at ultrahigh pressures and temperatures, J. Appl. Phys. 107 (2010) 093528.

[34] B.K. Godwal, J. Yan, S.M. Clark, R. Jeanloz, High-pressure behavior of osmium: an analog for iron in earth's core, J. Appl. Phys. 111 (2012) 112608.

[35] C.S. Perreault, N. Velisavljevic, Y.K. Vohra, High-pressure structural parameters and equation of state of osmium to $207 \mathrm{GPa}$, Cogent Phys. 4 (2017) 1376899.

[36] C. Pantea, I. Mihut, H. Ledbetter, J.B. Betts, Y. Zhao, L.L. Daemen, H. Cynn, A. Migliori, Bulk modulus of osmium, 4-300 K, Acta Mater. 57 (2009) 544-548.

[37] B.R. Sahu, L. Kleinman, Osmium is not harder than diamond, Phys. Rev. B72 (2005) 113106.

[38] X.H. Deng, W. Lu, Y.M. Hu, H.S. Gu, The elastic properties of hexagonal osmium under pressure: the first-principles investigations, Physica B 404 (2009) 1218-1221. 
[39] K.D. Joshi, S.C. Gupta, S. Banerjee, Shock Hugoniot of osmium up to $800 \mathrm{GPa}$ from first principles calculations, J. Phys.: Condens. Matter 21 (2009) 415402.

[40] Liu Bo, Gu Mu, Liu Xiao-Lin, Huang Shi-Ming, Ni Chen, Li Ze-Ren, Wang Rong-Bo, Firstprinciples study of lattice dynamics and thermodynamics of osmium under pressure, Chinese Phys. 19 (2) (2010) 026301.

[41] Chun-Mei Liu, Yan Cheng, Bo Zhu, Guang-Fu Ji, Structural and thermodynamic properties of Os from first-principles calculations, Physica B406 (2011) 2110-2115.

[42] Feng Peng, Dong Chen, Hongzhi Fu, Xiangdong Yang, Elastic and thermal properties of osmium under pressure, Philos. Mag. Lett. 91 (1) (2011) 43-53.

[43] Ke Liu, Duan-Wei He, Xiao-Lin Zhou, Hai-Hua Chen, First-principles study of structural and thermodynamic properties of osmium, Physica B406 (2011) 3065-3069.

[44] Xiaohui Deng, Wenwei Wang, Dengyu Zhang, Kaiming You, Detailed investigation of thermodynamic properties of hexagonal osmium using the ab-initio technique, Physica B406 (2011) 656-662.

[45] A. Rubio-Ponce, D. Olguín, R. de Coss, Ab-initio study of the structural and electronic properties of osmium under high pressure, J. Phys. Conf. Ser. 410 (2013) 012049.

[46] S. Ahmed, M. Zafar, M. Shakil, M.A. Choudhary, Density functional theory study of structural, electronic, and thermal properties of Pt, Pd, Rh, Ir, Os and PtPdX (X=Ir, Os, and Rh) alloys, Chinese Phys. 25 (3) (2016) 036501.

[47] L. Burakovsky, N. Burakovsky, D.L. Preston, Ab initio melting curve of osmium, Phys. Rev. B92 (2015) 174105.

[48] T. Górecki, Vacancies and melting curves of metals at high pressure, Z. Met.kd. 66 (3) (1977) 231-236.

[49] E.Y. Kulyamina, V.Y. Zitserman, L.R. Fokin, Osmium: melting curve and matching of hightemperature data, High Temp. 53 (1) (2015) 151-154.

[50] N.N. Patel, M. Sunder, High pressure melting curve of osmium up to $35 \mathrm{GPa}$, J. Appl. Phys. 125 (2019) 055902.

[51] P.-F. Paradis, T. Ishikawa, N. Koike, Physical properties of equilibrium and nonequilibrium liquid osmium measured by levitation techniques, J. Appl. Phys. 100 (2006) 103523.

[52] J.W. Arblaster, What is the true melting point of osmium?, Platin. Met. Rev. 49 (4) (2005) 166-168.

[53] L.I. Voronova, V.P. Polyakova, E.M. Savitskii, Alloys of the system Pt-Os, Russ. Metall. (5) (1984) 201-203.

[54] P.S. Rudman, Lattice parameters of some h.c.p. binary alloys of rhenium and osmium: Re-W, Re-Ir, Re-Pt; Os-Ir, Os-Pt, J. Less-Common Met. 12 (1967) 79-81.

[55] S.A. Gromilov, T.V. D'yachkova, A.P. Tyutyunnik, Y.G. Zainulin, A.I. Gubanov, S.V. Cherepanova, The products of thermobaric treatment of $\mathrm{Pt}_{0.25} \mathrm{Os}_{0.75}$, J. Struct. Chem. 49 (2) (2008) 382-385.

[56] S. Schönecker, X. Li, M. Richter, L. Vitos, Lattice dyanamics and metastability of fcc metals in the hcp structure and the crucial role of spin-orbit coupling in platinum, Phys. Rev. B97 (2018) 224305.

[57] A. Fernández Guillermet, Critical evaluation of the thermodynamic properties of molybdenum, Int. J. Thermophys. 6 (4) (1985) 367-393.

[58] Cuiping Guo, Z. Du, Thermodynamic optimization of the Mn-Ni system, Intermetallics 13 (2005) 525-534.

[59] Xiao-Gang Lu, Qing Chen, A CALPHAD Helmholtz energy approach to calculate thermodynamic and thermophysical properties of fcc Cu, Philos. Mag. 89 (25) (2009) 21672194.

[60] M.H.G. Jacobs, R. Schmid-Fetzer, Thermodynamic properties and equation of state of fcc aluminum and bcc iron, derived from a lattice vibrational method, Phys. Chem. Miner. 37 (10) (2010) 721-739. 
[61] A. Karbasi, S.K. Saxena, R. Hrubiak, The thermodynamics of several elements at high pressure, Calphad: Comput. Coupling Phase Diagrams Thermochem. 35 (2011) 72-81.

[62] R. Hrubiak, V. Drozd, A. Karbasi, S.K. Saxena, High P-T phase transitions and P-V-T equation of state of hafnium, J. Appl. Phys. 111 (2012) 112612.

[63] M.H.G. Jacobs, R. Schmid-Fetzer, A.P. van den Berg, An alternative use of Kieffers's lattice dynamics model using vibrational density of states for constructing thermodynamic databases, Phys. Chem. Miner. 40 (2013) 207-227.

[64] X. Liu, K. Oikawa, Assessment of the temperature and pressure dependence of molar volume and phase diagrams of $\mathrm{Cu}$ and $\mathrm{Zn}$, Calphad: Comput. Coupling Phase Diagrams Thermochem. 47 (2014) 114-122.

[65] X. Liu, K. Oikawa, Assessment of temperature and pressure dependence of molar volume and phase diagrams of binary Al-Si systems, Mater. Trans. 55 (11) (2014) 1673-1682.

[66] N. Bourgeois, J.-C. Crivello, A. Saengdeejing, Y. Chen, P. Cenedese, J.-M. Joubert, Thermodynamic modeling of the Ni-H system, J. Phys. Chem. C 119 (2015) 24546-24557. https://doi.org/10.1021/acs.jpcc.5b06393.

[67] Zhifeng Xu, Xin Guo, Xiao-Gang Lu, Study of thermodynamic and thermophysical properties of fcc Pt through CALPHAD approach, Shanghai Met. 038 (6) (2016) 71-76.

[68] Y. Fei, E. Brosh, Experimental study and thermodynamic calculations of phase relations in the Fe-C system at high pressure, Earth Planet. Sc. Lett. 408 (2014) 155-162.

[69] D. Huang, S. Liu, Y. Du, B. Sundman, Modeling of the molar volume of the solution phases in the Al-Cu-Mg system, Calphad: Comput. Coupling Phase Diagrams Thermochem. 51 (2015) 261-271.

[70] M. Emuna, Y. Greenberg, R. Hevroni, I. Korover, E. Yahel, G. Makov, Phase diagrams of binary alloys under pressure, J. Alloys Compd. 687 (2016) 360-369.

[71] G. Makov, M. Emuna, E. Yahel, H.G. Kim, J. Lee, Effect of pressure on the interactions and phase diagrams of binary alloys, Comput. Mater. Sci. 169 (2019) 109103.

[72] E. Brosh, G. Makov, R.Z. Shneck, Application of Calphad to high pressures, Comput. Coupling Phase Diagr. Thermochem. 31 (2007) 173-185. 
Supplementary materials to:

Modification of Lu's (2005) high pressure model for improved high pressure/high temperature extrapolations. Part II: modeling of osmium-platinum system at high pressure/high temperature

Jean-Marc Joubert ${ }^{1}$, Jean-Claude Crivello ${ }^{1}$, Kirill V. Yusenko ${ }^{2}$

${ }^{1}$ Univ Paris Est Creteil, CNRS, ICMPE, UMR 7182, 2 rue Henri Dunant, 94320 Thiais, France

${ }^{2}$ BAM Federal Institute for Materials Research in Testing, Berlin, Germany

e-mail address of corresponding author: joubert@icmpe.cnrs.fr

\section{Comparison of the three functionals used for the DFT calculation of hcp Os}

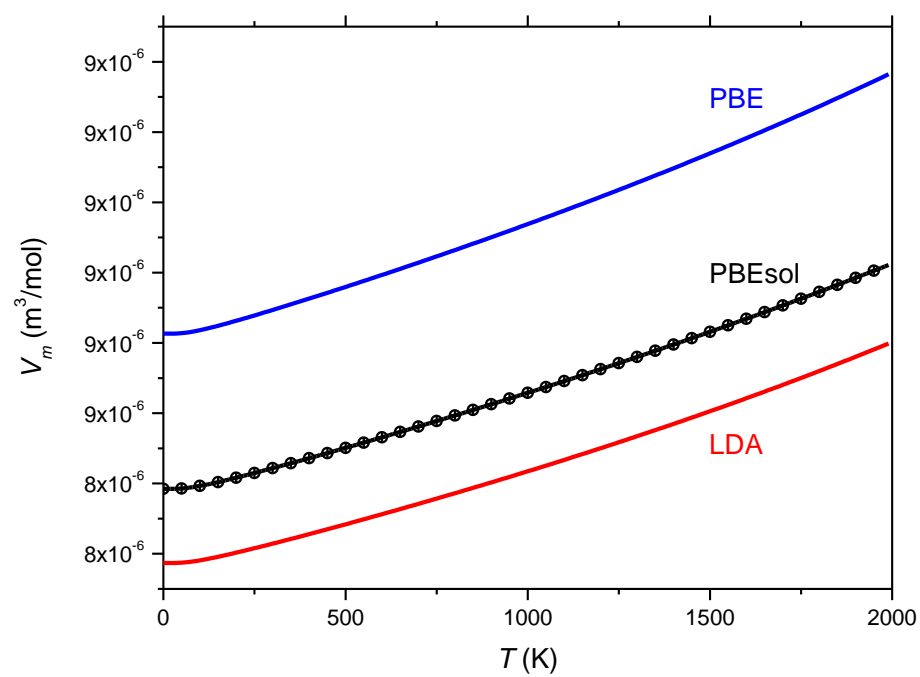

Figure 1: Molar volume of $h c p$ Os as a function of temperature calculated with three different functionals. 


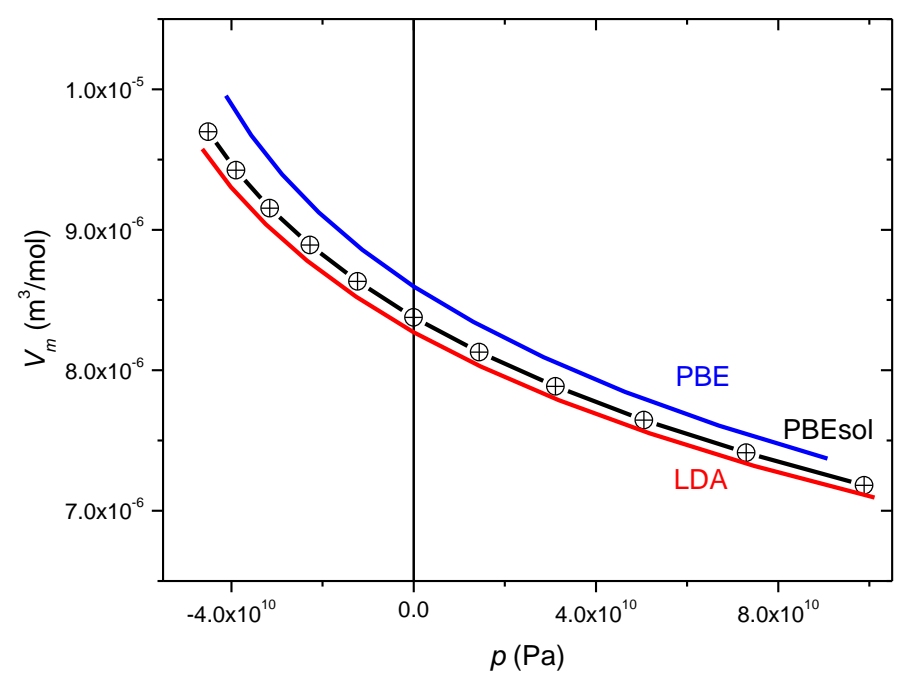

Figure 2: Molar volume of $h c p$ Os as a function of pressure at $0 \mathrm{~K}$ calculated with three different functionals.

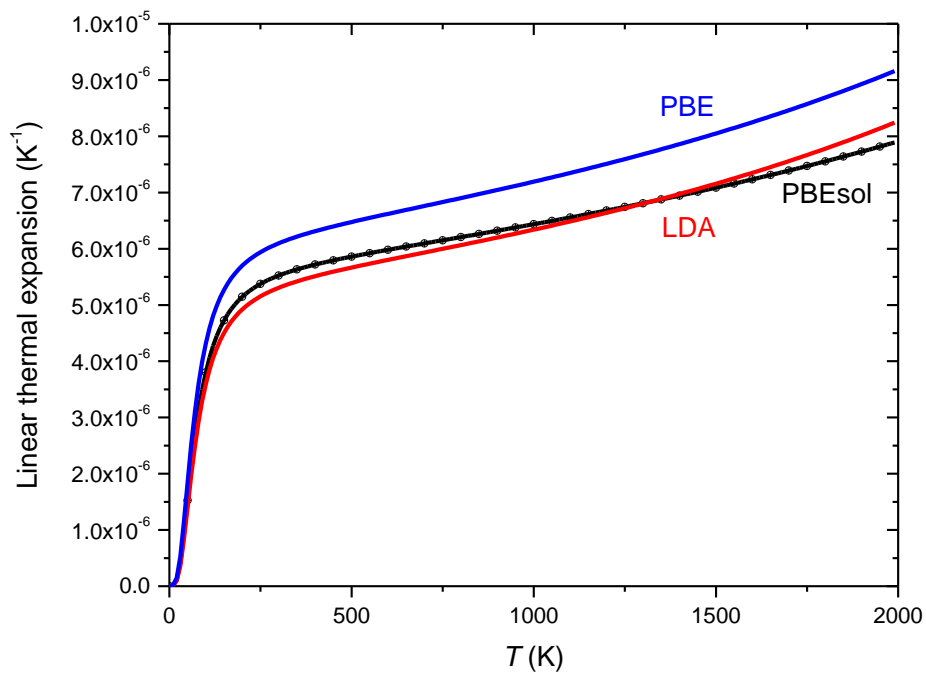

Figure 3: Linear thermal expansion of hcp Os as a function of temperature calculated with three different functionals. 


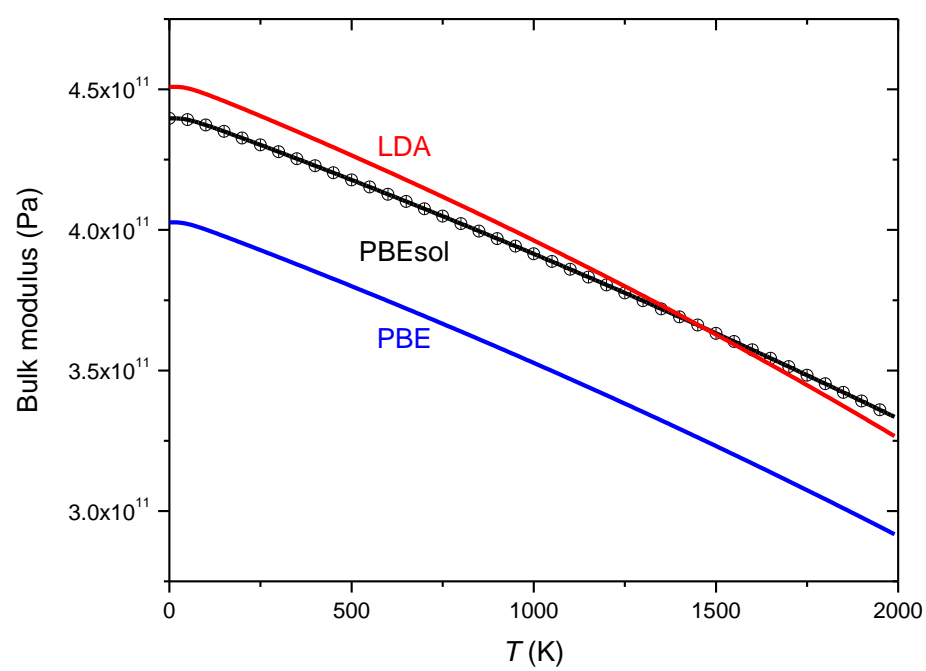

Figure 4: Bulk modulus of $h c p$ Os as a function of temperature calculated with three different functionals.

\section{Evaluation of the properties of $f c c$ Os}

Table 1 presents the reported lattice parameters and bulk modulus for $f c c$ Os in the literature. When available the comparison with the $h c p$ calculated in the same conditions is made.

Figs. 5 to 8 show the molar volume and the bulk modulus of $f c c$ Os and the difference of molar volume and bulk modulus with the $h c p$ phase.

The difference values chosen here for the modeling are those calculated in the present work.

Table 1: Bulk modulus and molar volume of $f c c$ and $h c p$ Os calculated by DFT.

\begin{tabular}{|c|c|c|c|c|c|c|c|c|c|c|}
\hline Reference & Technique & $\begin{array}{c}B_{f c c} \\
(\mathrm{GPa}) \\
\end{array}$ & $\begin{array}{c}B_{h c p} \\
(\mathrm{GPa}) \\
\end{array}$ & $\begin{array}{c}B_{f c c}-B_{h c p} \\
(\mathrm{GPa}) \\
\end{array}$ & $a_{f c c}(\AA)$ & $a_{h c p}(\AA ̊)$ & $c_{h c p}(\AA ̊)$ & $\begin{array}{c}V_{f c c} \\
\left(\mathrm{~m}^{3} / \mathrm{mol}\right)\end{array}$ & $\begin{array}{c}V_{h c p} \\
\left(\mathrm{~m}^{3} / \mathrm{mol}\right) \\
\end{array}$ & $\begin{array}{r}V_{f c c}-V_{h c p} \\
\left(\mathrm{~m}^{3} / \mathrm{mol}\right) \\
\end{array}$ \\
\hline [1] & LDA no $h c p$ & 419 & & & 3.83 & & & $8.460 \mathrm{E}-06$ & & \\
\hline \multirow[t]{2}{*}{ [2] } & LDA & 441.28 & 453.59 & -12.31 & 3.814 & 2.720 & 4.311 & $8.356 \mathrm{E}-06$ & $8.321 \mathrm{E}-06$ & $3.44 \mathrm{E}-08$ \\
\hline & GGA & 392.87 & 401.3 & -8.43 & 3.866 & 2.758 & 4.367 & 8.703E-06 & 8.660E-06 & $4.27 \mathrm{E}-08$ \\
\hline \multirow[t]{2}{*}{ [3] } & LDA & 438.7 & 447 & -8.3 & 3.799 & 2.716 & 4.275 & $8.256 \mathrm{E}-06$ & $8.225 \mathrm{E}-06$ & $3.13 \mathrm{E}-08$ \\
\hline & $\mathrm{LDA}+\mathrm{U} 2 \mathrm{eV}$ & 372.9 & 407.7 & -34.8 & 3.83 & 2.724 & 4.32 & $8.460 \mathrm{E}-06$ & $8.360 \mathrm{E}-06$ & $9.95 \mathrm{E}-08$ \\
\hline \multirow[t]{2}{*}{ [4] } & GGA & 399.66 & 404.11 & -4.45 & 3.857 & 2.749 & 4.335 & $8.642 \mathrm{E}-06$ & $8.543 \mathrm{E}-06$ & $9.86 \mathrm{E}-08$ \\
\hline & LDA & 434.42 & 462.11 & -27.69 & 3.806 & 2.714 & 4.274 & $8.303 E-06$ & 8.207E-06 & $9.60 \mathrm{E}-08$ \\
\hline [5] & FLAPW & 385.64 & 390.74 & -5.1 & 3.872 & 2.770 & 4.368 & $8.738 \mathrm{E}-06$ & 8.736E-06 & 2.57E-09 \\
\hline [6] & $\begin{array}{l}\text { FPLO-LDA } \\
\text { no } h c p\end{array}$ & 432 & & & 3.817 & & & 8.374E-06 & & \\
\hline present work & PBEsol & 431 & 440 & -9 & 3.822 & & & $8.408 \mathrm{E}-06$ & $8.378 \mathrm{E}-06$ & $3.00 \mathrm{E}-08$ \\
\hline
\end{tabular}




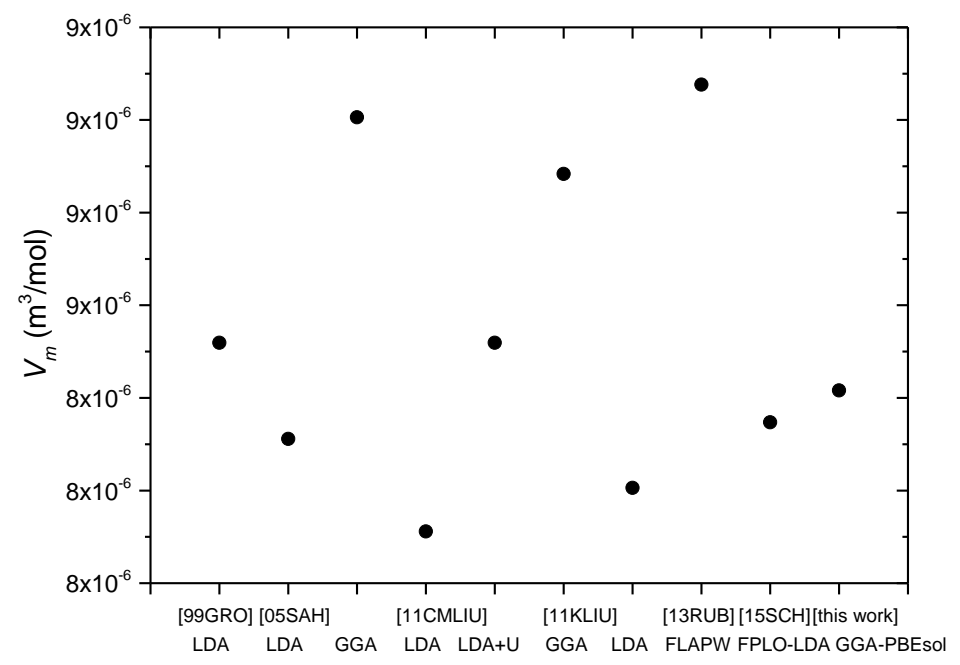

Figure 5: Molar volume of $f c c$ Os. Calculated data are from Refs. [1] [99GRO], [2] [05SAH], [3] [11CMLiu], [4] [11Kliu], [5] [13RUB], [6] [15SCH] and this work.

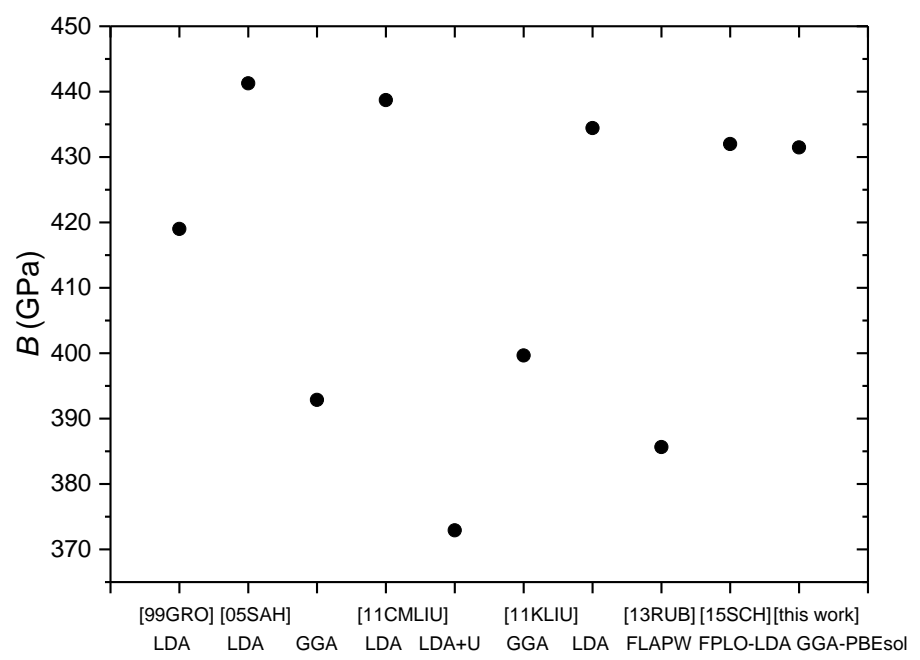

Figure 6: Bulk modulus of $f c c$ Os. Calculated data are from Refs. [1] [99GRO], [2] [05SAH], [3] [11CMLiu], [4] [11Kliu], [5] [13RUB], [6] [15SCH] and this work. 


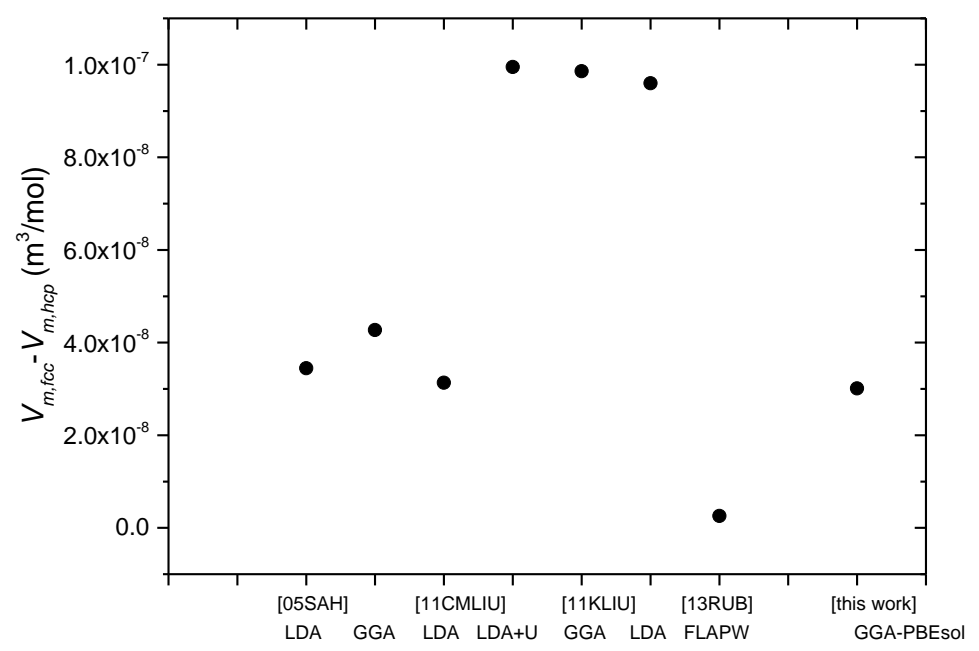

Figure 7: Molar volume difference between $f c c$ and $h c p$ Os. Calculated data are from Refs. [2] [05SAH], [3] [11CMLiu], [4] [11Kliu], [5] [13RUB] and this work.

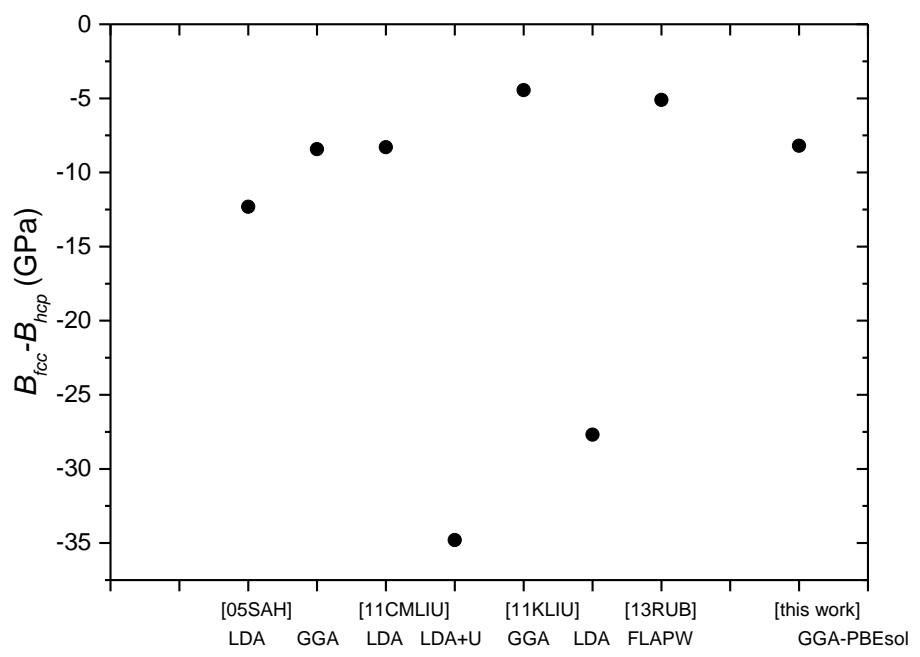

Figure 8: Bulk modulus difference between $f c c$ and $h c p$ Os. Calculated data are from Refs. [2] [05SAH], [3] [11CMLiu], [4] [11Kliu], [5] [13RUB] and this work. 


\section{References}

[1] J.C. Grossman, A. Mizel, M. Côté, M.L. Cohen, S.G. Louie, Transition metals and their carbides and nitrides: trends in electronic and structural properties, Phys. Rev. B60 (9) (1999) 6343-6347.

[2] B.R. Sahu, L. Kleinman, Osmium is not harder than diamond, Phys. Rev. B72 (2005) 113106

[3] Chun-Mei Liu, Yan Cheng, Bo Zhu, Guang-Fu Ji, Structural and thermodynamic properties of Os from first-principles calculations, Physica B406 (2011) 2110-2115.

[4] Ke Liu, Duan-Wei He, Xiao-Lin Zhou, Hai-Hua Chen, First-principles study of structural and thermodynamic properties of osmium, Physica B406 (2011) 3065-3069.

[5] A. Rubio-Ponce, D. Olguín, R. de Coss, Ab-initio study of the structural and electronic properties of osmium under high pressure, Journal of Physics Conference Series 410 (2013) 012049.

[6] S. Schönecker, X. Li, K. Koepernik, B. Johansson, L. Vitos, M. Richter, Metastable cubic and tetragonal phases of transition metals predicted by density-functional theory, RSC Advances 5 (2015) 69680. 
\$ Os-Pt high pressure

$\begin{array}{llllll}\text { ELEMENT } & \text { - } & \text { ELECTRON_GAS } & 0.0000 \mathrm{E}+00 & 0.0000 \mathrm{E}+00 & 0.0000 \mathrm{E}+00 ! \\ \text { ELEMENT VA } & \text { VACUUM } & 0.0000 \mathrm{E}+00 & 0.0000 \mathrm{E}+00 & 0.0000 \mathrm{E}+00 ! \\ \text { ELEMENT OS } & \text { HCP_A3 } & 1.9020 \mathrm{E}+02 & 0.0000 \mathrm{E}+00 & 3.2635 \mathrm{E}+01 ! \\ \text { ELEMENT PT } & \text { FCC_A1 } & 1.9508 \mathrm{E}+02 & 5.7237 \mathrm{E}+03 & 4.1631 \mathrm{E}+01 !\end{array}$

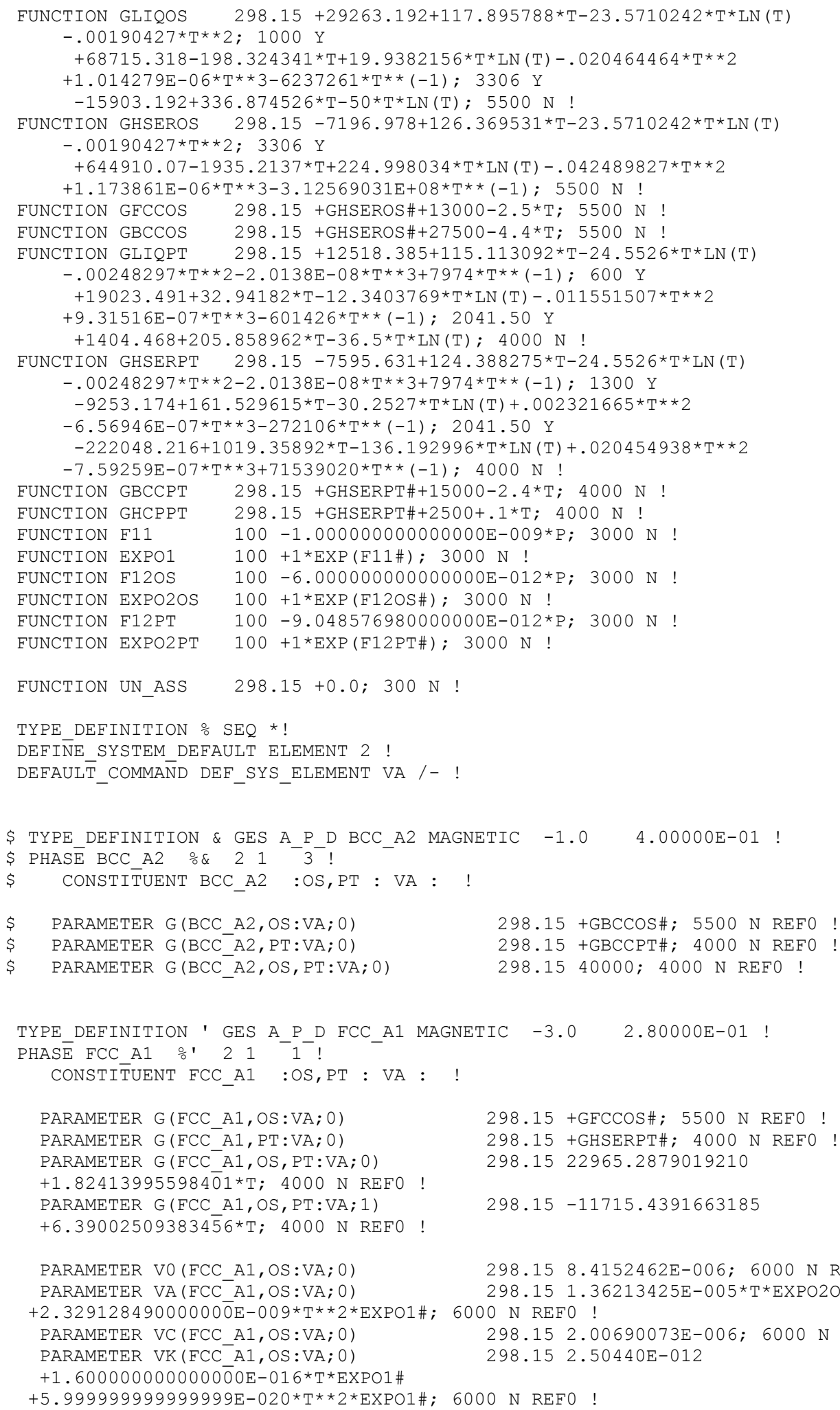




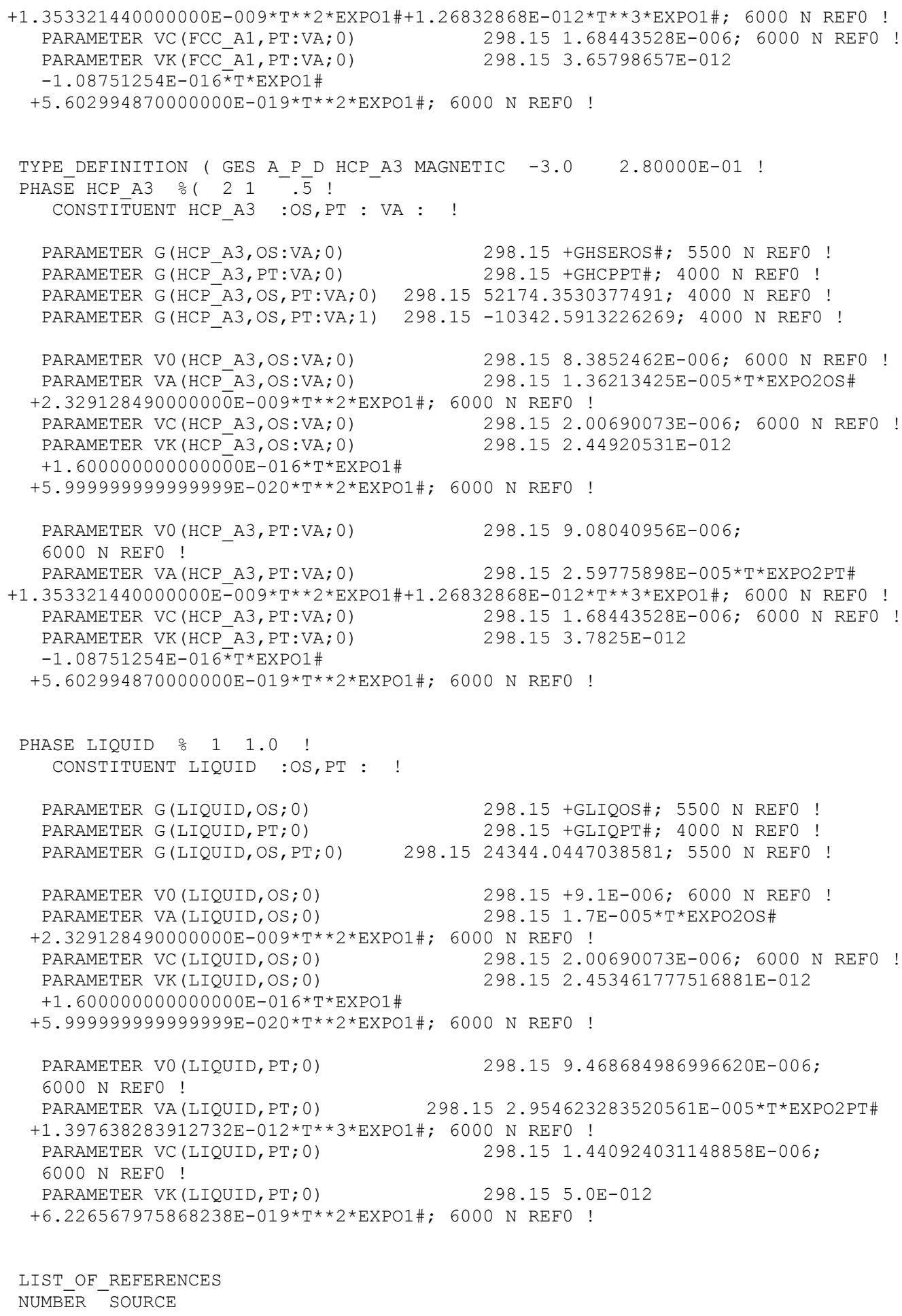

